\title{
Reconciling Introspective Utility with Revealed Preference: Experimental Arguments Based on Prospect Theory*
}

\author{
Mohammed Abdellaoui ${ }^{\mathrm{a}}$, Carolina Barrios ${ }^{\mathrm{a}}$, \\ Peter P. Wakker ${ }^{\mathrm{b}, * *}$ \\ ${ }^{a}$ GRID, CNRS, ENSAM \& ESTP, 30 Avenue du Président Wilson 94230 Cachan, \\ France \\ ${ }^{b}$ Dept. of Economics, University of Amsterdam, Roetersstraat 11, Amsterdam, 1018 \\ WB, The Netherlands, 31-(0)20.525.42.29 (O), 31-(0)20.525.41.26 (S), 31 (0)20 \\ 525.52.83 (F),P.P.Wakker@UvA.NL
}

April, 2005

Abstract

In an experiment, choice-based utility of money is derived from choices under risk, and choiceless utility from introspective strength-of-preference judgments. The wellknown inconsistencies of risky utility that result if the data are analyzed in terms of expected utility are resolved if the data are analyzed in terms of prospect theory. One consistent cardinal utility index for risky choice then results. Remarkably, this cardinal index also agrees well with the choiceless utilities. This finding suggests a relation between a choice-based and a choiceless concept. Such a relation would imply that introspective judgments can provide useful data for economics, and can reinforce the revealed-preference paradigm. Implications for the classical debate on ordinal versus cardinal utility are discussed.

\footnotetext{
${ }^{*}$ Mark Blaug, Denis Bouyssou, Itzhak Gilboa, Jean-Yves Jaffray, Edi Karni, Veronika Köbberling, Mark Machina, Chris Starmer, and Stefan Trautmann made helpful comments.

** Corresponding author: Peter P. Wakker, CREED, Dept. of Economics, University of Amsterdam, Roetersstraat 11, Amsterdam, 1018 WB, The Netherlands; 31-(0)20.525.42.29 (O), 31-(0)20.525.41.26 (S), 31-(0)20 525.52.83 (F); P.P.Wakker@uva.nl; http://www1.fee.uva.nl/creed/wakker.
} 


\section{Introduction}

Utility has been a controversial concept throughout the history of economics, with interpretations shifting over time. Since the beginning of the twentieth century, after what has become known as the ordinal revolution, utility has been taken as an ordinal concept, based solely on observable choice, in mainstream economics (Pareto 1906). Ordinalism has dominated economics ever since (Hicks \& Allen 1934).

Based on the many anomalies of observed choice that have been discovered in the twenthieth century, several authors have argued that a reinterpretation of utility broader than purely ordinal is relevant for mainstream economics. One of the earliest proponents was van Praag (1968), who used subjective questions to measure welfare. Recently, Kahneman (1994) initiated a stream of papers arguing for the relevance of experienced utility in economics. Such a broader reinterpretation was also advocated by a founder of the Econometric Institute of the Erasmus University, Jan Tinbergen (1991), who wrote in a special issue of the Journal of Econometrics on the measurement of utility and welfare:

The author believes in the measurability of welfare (also called satisfaction or utility). Measurements have been made in the United States (D.W. Jorgenson and collaborators), France (Maurice Allais), and The Netherlands (Bernard M.S. Van Praag and collaborators). The Israeli sociologists S. Levy and L. Guttman have shown that numerous noneconomic variables are among the determinants of welfare ... (p. 7).

This paper presents an investigation into broader interpretations of the utility of money, using an experimental approach. We will compare experimental measurements of choice-based and choiceless utilities, and investigate their relations. Our main finding will be that there are no systematic differences between the different measurements. This finding suggests that choiceless empirical inputs can be useful for the study and prediction of observable choice. Let us emphasize that we make this suggestion only for choiceless empirical inputs that can be firmly related to observable choice. These choiceless inputs should reinforce, rather than renounce, the achievements of the ordinal revolution.

Expected utility provides a firm basis for rational decisions and for Bayesian statistics (Kahneman \& Tversky 1979, p. 277; Savage 1954; Zellner 1971). It is also used as a basis for most descriptive economic measurements of utility today, in which 
risk attitudes are to be captured entirely in terms of utility curvature. This approach is so widespread that it has been ingrained in standard economic terminology, with utility curvature usually described as "risk aversion" or even, in econometric studies, as "individual preference." Many empirical studies have, however, revealed descriptive difficulties of expected utility (Starmer 2000). Descriptive improvements have been developed, such as prospect theory (Kahneman \& Tversky 1979, Tversky \& Kahneman 1992). Our analysis will first show, in agreement with previous findings (Herschey \& Schoemaker 1985), that utility measurement under expected utility leads to inconsistencies, which may explain why there haven't been many estimations of utility yet (Gregory, Lamarche, \& Smith 2002, p. 227). We next show that, by means of prospect theory, the inconsistencies can be resolved, and a consistent economic concept of utility can be restored.

\section{Outline of the Paper}

Section 2 briefly describes the history of utility in economics up to 1950 , focusing on the rise of ordinalism and ending with von Neumann and Morgenstern's (1944) contribution. This history was described before by Stigler (1950), Blaug (1962), and others. Because of new developments in utility theory during the last decades, an update of the history is called for. It is provided in Section 3. Two developments are distinguished. One took place in mainstream economics, where many empirical problems of revealed preference were discovered, leading Kahneman and others to propose new interpretations of utility (Subsection 3.1). The other development took place in decision theory and concerns the distinction between risky and riskless cardinal utility (Subsection 3.2). ${ }^{1}$ These developments will lead to the research question of this paper.

Section 4 gives notation and defines expected utility and prospect theory. Section 5 measures choice-based utilities through a recently introduced method, the tradeoff method, which is valid under expected utility but, contrary to classical methods, maintains its validity under prospect theory. Subsequently, choiceless cardinal utility is measured without using any choice making or risk. Remarkably, no significant differences are found between these two measurements of utility. A psychological explanation is given for the plausibility of the equality found. To verify that tradeoff

\footnotetext{
${ }^{1}$ We use "risky utility" as a shorthand for utility to be used for choices under risk, such as in expected utility.
} 
91 utilities do reflect choice making, Section 6 compares those utilities with utilities derived from a third, traditional, measurement method, that is also based on choice making, and that uses certainty equivalents of two-outcome prospects with a 1/3 probability for the best outcome. Again, no significant differences are found.

To verify that our design has the statistical power to detect differences, Section 6 also compares the utilities obtained up to that point with utilities derived from a fourth measurement method, again choice-based and again using certainty equivalents, but now of two-outcome prospects with a $2 / 3$ probability for the best outcome. When analyzed through expected utility, the utilities of the fourth method deviate significantly from those found through the other three methods, in agreement with the common findings in the literature (Karmarkar 1978), and falsifying expected utility. The discrepancy is resolved by reanalyzing the data by means of prospect theory.

103 This theory does not affect the first three measurements but it modifies the fourth.

104 After this modification, a complete reconciliation of all measurements obtains, leading to one utility function consistently measured in four different ways.

Section 7 acknowledges and discusses some criticisms that can be raised against our analysis, and compares our findings with other findings in the literature. Motivations and conclusions are in Section 8. Appendix A gives the details of our experimental method for eliciting indifferences, developed to minimize biases. Appendices B and D describe further statistical tests.

111 Appendix $\mathrm{C}$ describes parametric families of utility used in our study. We use 112 two traditional families but also introduce a new one-parameter family, the 113 expopower family, constructed from a more general two-parameter family of Saha 114 (1993). Our family, contrary to existing families, allows for the simultaneous

115 fulfillment of three economic desiderata: concave utility, decreasing absolute risk 116 aversion, and increasing relative risk aversion. There is much interest in such new 117 parametric families of utility. We nevertheless present this material in the appendix 118 because it is more technical than the rest of this paper.

119 In summary, by using prospect theory and the techniques of modern experimental 120 economics, our paper sheds new light on the measurement, interpretation, and 121 applicability of utility. 


\section{The History of Ordinal versus Cardinal Utility up to 1950}

124 The first appearances of utility were in Cramer (1728) and Bernoulli (1738), who

125 proposed expected utility as a solution to the St. Petersburg paradox. Utility was

126 presented as a general index of goodness and the authors did not explicitly restrict its

127 meaning to risky decisions. Bentham (1789) gave the first thorough discussion of

128 utility as a central concept in human behavior. Risk was not central in his analysis,

129 although it was mentioned occasionally. In the century that followed, economists used

130 utility as an, in modern terms cardinal, index of goodness. Although there were

131 concerns about the measurement of utility (Cooter and Rappoport 1984),

132 measurability was not a central issue. After the marginal revolution of the $1870 \mathrm{~s}$,

133 which showed the importance of comparisons of utility rather than absolute levels of

134 utility, diminishing marginal utility became the central hypothesis. Marshall (1890)

135 pointed out its equivalence to risk aversion, assuming that the expectation of the

136 utility in question governs risky decisions. Table 1 displays the various concepts of

137 utility, discussed hereafter.

TABLE 1. Various concepts of utility. The utilities within boxes are commonly required to be restricted to their domains, and not to be applied in other domains. $\Leftrightarrow$ : A relation between these two is obtained in this paper. It extends vNM (von Neumann-Morgenstern) risky utility beyond risk, and connects an economic, middlecolumn, concept with a "non-economic," right-column concept.

An important step forward was made at the beginning of the twentieth century,

152 Economists became concerned about the empirical observability of utility. Utility was

153 related to observable choice and all associations with introspective psychological

154 judgments were abandoned. This development changed the status of utility from

155 being ad hoc to being empirically well founded. Along with the concern for 
156 observability came the understanding of Pareto and others that, if the only purpose of

157 utility is to explain consumer choices, prices, and equilibria, as in the middle cell of

158 Table 1, then utility is ordinal. Any strictly increasing transformation can be applied

159 without affecting the empirical meaning, which implies that utility differences and

160 marginal utility are not meaningful.

161 Alt (1936), Frisch (1926), and others demonstrated that cardinal utility, which

162 does assign meaning to utility differences, can be formally derived from direct

163 strength-of-preference judgments, such as the judgment that the strength of preference

164 of $\$ 10$ over $\$ 0$ exceeds that of $\$ 110$ over $\$ 100$. Such judgments are based on

165 introspection and not on observable choice and are, therefore, considered meaningless

166 by most economists (Samuelson 1938a; Varian 1993 pp. 57-58). Hicks and Allen

167 (1934) strongly argued in favor of an ordinal view of utility, and this became the

168 dominant viewpoint in economics. Similar ideas, in agreement with logical

169 positivism, became popular in psychology, where behaviorism was propagated by

170 Watson (1913), Skinner (1971), and others.

171 New hope for the existence of cardinal utility was raised by von Neumann and

172 Morgenstern (1944), who derived cardinal utility for decision under risk; earlier

173 presentations of this idea were given by Ramsey (1931) and Zeuthen (1937). After

174 some debates, the consensus became that this risky index is cardinal in the

175 mathematical sense of being unique up to unit and origin, but not cardinal in the sense

176 of being the neo-classical index of goodness that emerged at the end of the $19^{\text {th }}$

177 century (Friedman and Savage 1948; Baumol 1958 p. 655; Varian 1993). ${ }^{2}$ Ordinalism

178 has continued to dominate in mainstream economics ever since.

179

\section{3. Ordinal versus Cardinal Utility after 1950}

181 This section describes the history of utility in the second half of the twentieth century,

182 which followed after the classic historical review by Stigler (1950) and after von

183 Neumann and Morgenstern's contribution.

\footnotetext{
${ }^{2}$ For recent deviating viewpoints, see Harsanyi (1978), Loomes and Sugden (1982), Ng (1997), and Rabin (2000, footnote 3). It is remarkable that von Neumann and Morgenstern used their cardinal utility not only to evaluate randomized strategies but also as a unit of exchange between players.
} 


\subsection{Ordinal Utility in the Economics Literature after 1950}

At the beginning of the ordinal period, promising results were obtained through preference representations and derivations of equilibria (Houthakker 1950; Samuelson 1938b; Savage 1954; Debreu 1959). Soon, however, problems arose (Allais 1953; Ellsberg 1961; Ng 1997 p. 1854; Sen 1974 p. 390; Simon 1955). Cardinal utilities, at least in a mathematical sense, could not be discarded entirely. They were needed, not only for risky decisions such as for mixed strategies in game theory (von Neumann \& Morgenstern 1944), but also for intertemporal evaluations (Samuelson 1937), for utilitarian welfare evaluations (Harsanyi 1955), for quality-of-life measurements in health (Gold et al. 1996), and for (-1 times the) loss functions in Bayesian statistics (Zellner 1971). The consensus became that such cardinal indexes are relevant, but should be restricted to the specific domain where they apply, and should not be equated to each other or to neo-classical cardinal utility (Samuelson 1937 p. 160).

The most serious blow for the revealed-preference paradigm may have been the discovery of preference reversals, entailing that revealed preferences can depend on economically irrelevant framing aspects even in the simplest choice situations (Grether and Plott 1979; Lichtenstein and Slovic 1971; Camerer 1995). Subsequently, numerous other choice anomalies have been discovered (Kahneman and Tversky 2000). It led Kahneman (1994) to argue that choiceless, "experienced," utility can provide useful information for economics in contexts where such choice anomalies prevail. Many other papers have argued for broader interpretations of utility than purely ordinal, e.g. Broome (1991), Frey and Stutzer (2000), Gilboa and Schmeidler (2001), Kapteyn (1994), Loomes and Sugden (1982), Rabin (2000 footnote 3), Robson (2001 Section III.D), Tinbergen (1991), van Praag (1968, 1991), and Weber (1994 p. 239). A drawback of extending the inputs of utility is, obviously, that predictions of economic decisions then can become difficult. The present paper presents an experimental investigation, based on prospect theory, into broader interpretations of utility, showing that they can positively contribute to economic predictions, rather than complicate them.

\subsection{Cardinal Utility in Decision Theory after 1950; Risky versus Riskless Utility}

Since the 1970s, several authors in decision theory have conducted empirical studies into the distinction between von Neumann-Morgenstern ("risky") and neo- 
216 classical cardinal utility. Contrary to the ordinalists, these authors assumed that

217 choiceless cardinal utility, and thereby marginal utility, is meaningful, and they

218 commonly used strength-of-preference judgments to measure it. As depicted in Table

219 1, choiceless cardinal utility can also be related to direct experience (Kahneman 1994).

220 Others have related it to just noticeable differences (Allais 1953; Edgeworth 1881), and

221 other psychophysical measurements (Breiter et al. 2001). In this study, we restrict

222 attention to strength of preferences for measuring choiceless utility. In decision theory,

223 such cardinal choiceless utility was usually called riskless utility. The difference

224 between marginal riskless utility and risk attitude has often been emphasized (Camerer

2251995 p. 619; Ellingsen 1994; Ellsberg 1954; Samuelson 1950 p. 121), and nonlinear

226 empirical relations between risky and riskless utility have been studied (Bouyssou and

227 Vansnick 1988; Debreu 1976; Pennings and Smidts 2000).

228 The classical decision-theoretic studies invariably assumed expected utility for

229 analyzing risky decisions. Under this assumption, a difference between marginal utility

230 and risk attitude necessarily implies that the corresponding utility functions must be in

231 different cardinal classes, that is, there must be a nonlinear relation between risky and

232 riskless utility. The main problem in this classical approach may have been the

233 empirical deficiency of expected utility (Camerer 1995). Different methods for

234 measuring risky utility, that should yield the same utilities, exhibited systematic

235 discrepancies (Karmarkar 1978; Hershey and Schoemaker 1985). These were as

236 pronounced as the differences between risky and riskless utility (McCord and de

237 Neufville 1983, p. 295). It led some authors working on risky versus riskless utility to

238 abandon the classical expected-utility approach. For example, Krzysztofowicz and

239 Koch (1989) and McCord and de Neufville (1984) suggested that nonexpected utility

240 theories will better accommodate the discrepancies between marginal utility and risk

241 attitude than nonlinear transformations between risky and riskless utility.

242 Since the 1980s, many models that deviate from expected utility have been

243 proposed (Camerer 1995; Machina 1982, Starmer 2000). Popular examples are rank-

244 dependent utility (Gilboa 1987; Quiggin 1982; Schmeidler 1989; Yaari 1987) and

245 prospect theory (Tversky and Kahneman 1992). Rank-dependent utility and prospect

246 theory agree on the domain considered in this paper, i.e. two-outcome prospects with

247 known probabilities. These theories assume nonadditive probability weighting. They

248 provide better empirical predictions than expected utility and explain the

249 discrepancies between different utility measurements. 
Several authors have suggested that utility measurement can be improved through prospect theory (Bayoumi and Redelmeier 2000; Bleichrodt, Pinto, and Wakker 2001;

252 Krzysztofowicz and Koch 1989). Before, Fellner (1961 p. 676) suggested the same

253 basic idea. Under prospect theory, aspects of risk attitude not captured by marginal

254 utility can be explained by probability weighting, so that the main reason to distinguish

255 between risky and riskless utility disappears. The experimental findings of this paper

256 will, indeed, find no systematic difference between risky and riskless utility if the data

257 are analyzed in terms of prospect theory.

\section{Expected Utility and Prospect Theory}

261 Throughout this paper, $U: \mathbb{R} \rightarrow \mathbb{R}$ denotes a utility function of money that is strictly

262 increasing. We examin situations in which $U$ is measurable or cardinal in a 263 mathematical sense, i.e. $\mathrm{U}$ is determined up to unit and origin. The same symbol $\mathrm{U}$

264 will be used for utilities measured through strength of preferences as for utilities 265 measured through risky choices under various theories, even though a priori these

266 utilities may be different. The meaning of $U$ will be clear from the context. The

267 different interpretations of $U$ for strength of preference, expected utility, rank-

268 dependent utility, and prospect theory (where the term value function is often used)

269 will be discussed in Section 6.

270 By $(\mathrm{p}, \mathrm{x} ; \mathrm{y})$ we denote a monetary prospect yielding outcome $\mathrm{x}$ with probability $\mathrm{p}$

271 and outcome y otherwise. Expected utility $(E U)$ assumes that a utility function $\mathrm{U}$

272 exists such that the prospect is evaluated by $\mathrm{pU}(\mathrm{x})+(1-\mathrm{p}) \mathrm{U}(\mathrm{y})$. It is well known that

$273 \mathrm{U}$ is cardinal in the mathematical sense of being unique up to unit and origin. ${ }^{3}$

274 Prospect theory assumes that probabilities are weighted nonlinearly, by the

275 probability weighting function, denoted $\mathrm{w}$. The prospect theory $(P T)$ value of a

276 prospect $(p, x ; y)$ is $w(p) U(x)+(1-w(p)) U(y)$, where it is assumed that $x \geq y \geq 0$. EU

277 is the special case where $\mathrm{w}$ is the identity. For the prospects considered in this paper,

278 that only yield gain outcomes, original prospect theory (Kahneman \& Tversky, 1979,

279 Eq. 2), rank-dependent utility (Quiggin, 1982), and their combination, cumulative

\footnotetext{
${ }^{3}$ It need not be cardinal in the sense of being the neo-classical index of goodness that emerged at the end of the 19th century (Baumol 1958 p. 655).
} 
280 prospect theory (Tversky \& Kahneman, 1992), agree. Gul's (1991) disappointment

281 theory also agrees with these theories on our domain of two-outcome prospects, and,

282 therefore, our conclusions hold under this theory as well. On the domain considered,

283 original prospect theory is not subject to the theoretical problems that have been

284 pointed out for other choices (Handa 1977; Fishburn 1978). The normalization U(0)

$285=0$, necessary in prospect theory when loss outcomes are present, is not required in

286 our domain because it does not affect preferences here.

287 Similar to the utility function, the function $w$ is subjective and depends on the

288 individual, reflecting sensitivity towards probabilities. Many empirical investigations

289 have studied the shape of w. Figure 1 depicts the prevailing shape (Abdellaoui 2000;

290 Bleichrodt \& Pinto 2000; Camerer \& Ho 1994; Gonzalez \& Wu 1999; Kachelmeier \&

291 Shehata 1992; Karni \& Safra 1990; Prelec 1998; Quiggin 1982; Tversky \& Kahneman

292 1992; Yaari 1965). For counter-evidence, see Birnbaum \& Navarrete (1998) and

293 Harbaugh, Krause, \& Vesterlund (2002).

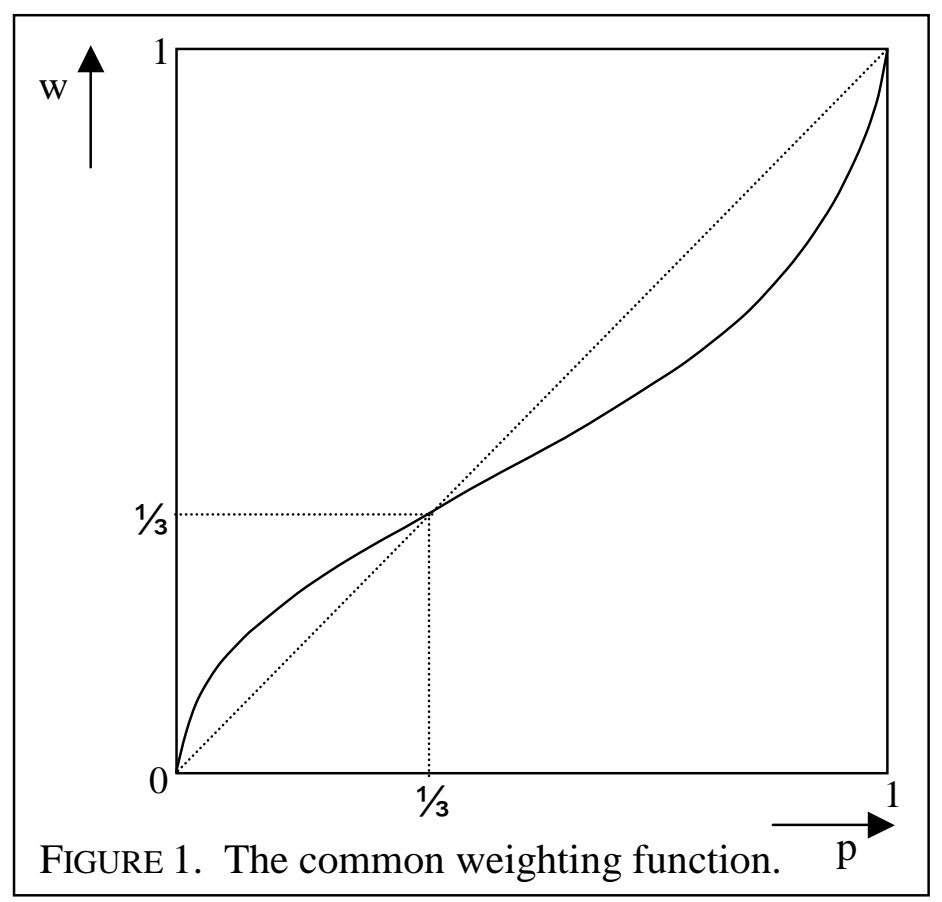

Under expected utility, all risk aversion has to be captured through concave utility whereas under the descriptively more realistic prospect theory, part of the observed risk aversion is due to probability weighting. This suggests that classical

311 estimations of utility are overly concave. A theoretical justification for this claim was 312 provided by Rabin (2000). Our paper will provide data that supports Rabin's claims, 313 and will show that prospect theory can explain these data. 


\section{An Experimental Comparison of Choice-Based and Choiceless Utilities}

316 This section presents the first two measurement methods, the, choice-based, tradeoff method and the, choiceless, strength-of-preference method.

Participants and Stimuli. We recruited 50 students from the department of economics of the Ecole Normale Supérieure of Cachan. Each participant was paid FF 150 ( $\$ 1 \approx$

321 FF6). No performance-based payments could be used for reasons discussed in

322 Section 7. Each participant was interviewed individually by means of a computer

323 program, in the presence of the experimenter. The participants were familiar with

324 probabilities and expectations but had not received a training in decision theory before

325 the experiment. Prior to the experimental questions, the participants were

326 familiarized with the stimuli through some practice questions. Three participants

327 were discarded because they gave erratic answers and apparently did not understand

328 the instructions; $\mathrm{N}=47$ participants remained.

329 Our choice-based method concerns risky choices. Only degenerate or two-

330 outcome prospects were used. They were displayed as pie charts on a computer

331 screen, where different colors were used to designate different areas; see Appendix A.

332 The units of payment in the prospects were French Francs. At the beginning of the

333 experiment, a random device repeatedly picked random points from the pie charts so

334 as to familiarize the participants with the representation of probabilities used in this

335 experiment.

336 The measurements of this paper are based on indifferences. It is well known that

337 observations of indifferences are prone to many biases, in particular if derived from

338 direct matching. Indifferences derived from choices seem to be less prone to biases

339 (Bostic, Herrnstein, \& Luce 1990; Tversky \& Kahneman 1992 p. 306). We

340 developed software for carefully observing indifferences while avoiding biases.

341 Appendix A gives details. We assessed three to six points for fitting the utility

342 functions; using such numbers of points was recommended by von Winterfeldt \&

343 Edwards (1986, p. 254).

344 We used a within-subject design, with all measurements carried out for all

345 individuals. All statistical analyses are based on within-subject differences. The

346 tradeoff method was always carried out before the other methods because its answers 
347 served as inputs in further elicitations, so as to simplify the comparisons. The order

348 of the other methods was counterbalanced so as to minimize systematic memory

349 effects, which is especially important for the strength of preference measurements.

351 Measurement methods. For the tradeoff method (TO method), we used "gauge

352 outcomes" $\mathrm{R}$ and $\mathrm{r}$ with $\mathrm{R}=\mathrm{FF} 2000>\mathrm{r}=\mathrm{FF} 1000$. An outcome $\mathrm{t}_{0}$ was set at FF 5000

353 (FF $1 \approx \$ 0.17)$. For each participant, the outcome $t_{1}>t_{0}$ was assessed such that $\left(1 / 3, t_{1}\right.$;

$354 \mathrm{r}) \sim\left(1 / 3, \mathrm{t}_{0} ; \mathrm{R}\right)$. Next, $\mathrm{t}_{2}>\mathrm{t}_{1}$ was assessed such that $\left(1 / 3, \mathrm{t}_{2} ; \mathrm{r}\right) \sim\left(1 / 3, \mathrm{t}_{1} ; \mathrm{R}\right), \ldots$, and,

355 finally, $\mathrm{t}_{6}>\mathrm{t}_{5}$ was assessed such that $\left(1 / 3, \mathrm{t}_{6} ; \mathrm{r}\right) \sim\left(1 / 3, \mathrm{t}_{5} ; \mathrm{R}\right)$. Under prospect theory, the

356 indifferences imply the five equalities $\mathrm{U}\left(\mathrm{t}_{6}\right)-\mathrm{U}\left(\mathrm{t}_{5}\right)=\cdots=\mathrm{U}\left(\mathrm{t}_{1}\right)-\mathrm{U}\left(\mathrm{t}_{0}\right)$, independently

357 of how the participant transforms probabilities (Wakker \& Deneffe 1996). Because

358 EU is a special case of PT with a linear weighting function, the five equalities also

359 hold under EU. Setting, as throughout this paper, $U\left(t_{0}\right)=0$ and $U\left(t_{6}\right)=1$, we obtain

360 the following equalities.

$$
\mathrm{U}\left(\mathrm{t}_{\mathrm{i}}\right)=\frac{\mathrm{i}}{6} \text { for all } \mathrm{i}
$$

362 The TO observations can be interpreted as direct observations of the inverse utility 363 function, with $t_{i}=U^{\text {inv }}(i / 6)$ for all $i$.

364 Our choiceless method for measuring utility is based on direct strength-of-

365 preference judgments (SP method). For each participant, an amount $\mathrm{s}_{2}$ was assessed

366 such that the strength of preference between $s_{2}$ and $t_{1}$ was judged to be the same as

367 between $t_{1}$ and $t_{0}$, the values obtained from the TO method (for details see Appendix

368 A). Similarly, we elicited amounts $s_{3}, \ldots, s_{6}$ such that the strength of preference

369 between $s_{i}$ and $s_{i-1}$ was judged to be the same as that between $t_{1}$ and $t_{0}$, for all $i$.

370 Following Alt (1936) and others, the SP method assumes that strength-of-preference

371 judgments correspond with utility differences, implying

$372 \mathrm{U}\left(\mathrm{s}_{6}\right)-\mathrm{U}\left(\mathrm{s}_{5}\right)=\ldots=\mathrm{U}\left(\mathrm{s}_{3}\right)-\mathrm{U}\left(\mathrm{s}_{2}\right)=\mathrm{U}\left(\mathrm{s}_{2}\right)-\mathrm{U}\left(\mathrm{t}_{1}\right)=\mathrm{U}\left(\mathrm{t}_{1}\right)-\mathrm{U}\left(\mathrm{t}_{0}\right)$.

373 Using the scaling convention $\mathrm{U}\left(\mathrm{t}_{1}\right)-\mathrm{U}\left(\mathrm{t}_{0}\right)=1 / 6$ (as in Eq. 5.1), we have

$$
\mathrm{U}\left(\mathrm{s}_{\mathrm{i}}\right)=\frac{\mathrm{i}}{6} \text { for all } \mathrm{i}
$$

375 Note that these strength-of-preference measurements indeed do not involve observed 376 choices in the sense of revealed preferences (Samuelson 1938a; Varian 1993). The 
various attempts to relate strength-of-preference judgments to choice making in a theoretical model after all, through side payments such as hours of labor, repeated or probabilistic choices, etc., are all based on separability assumptions that beg the question of cardinal utility. Strengths of preferences have, therefore, not been part of the commonly accepted empirical domain under the ordinal view of utility.

Analysis. In each test in this paper, the null hypothesis $\mathrm{H}_{0}$ assumes identical utility functions for the various methods. For testing group averages, we considered paired $t$-tests and Wilcoxon signed rank tests, all two-tailed, which always gave the same results. Conclusions based on accepted null hypotheses are most convincing under the most powerful tests, i.e. the $t$-tests. Hence, we usually report those. To reckon with individual differences, our main conclusions, presented in later sections, will be based on analysis of variance with repeated measures whenever possible. These analyses always give the same conclusions as paired $t$-tests.

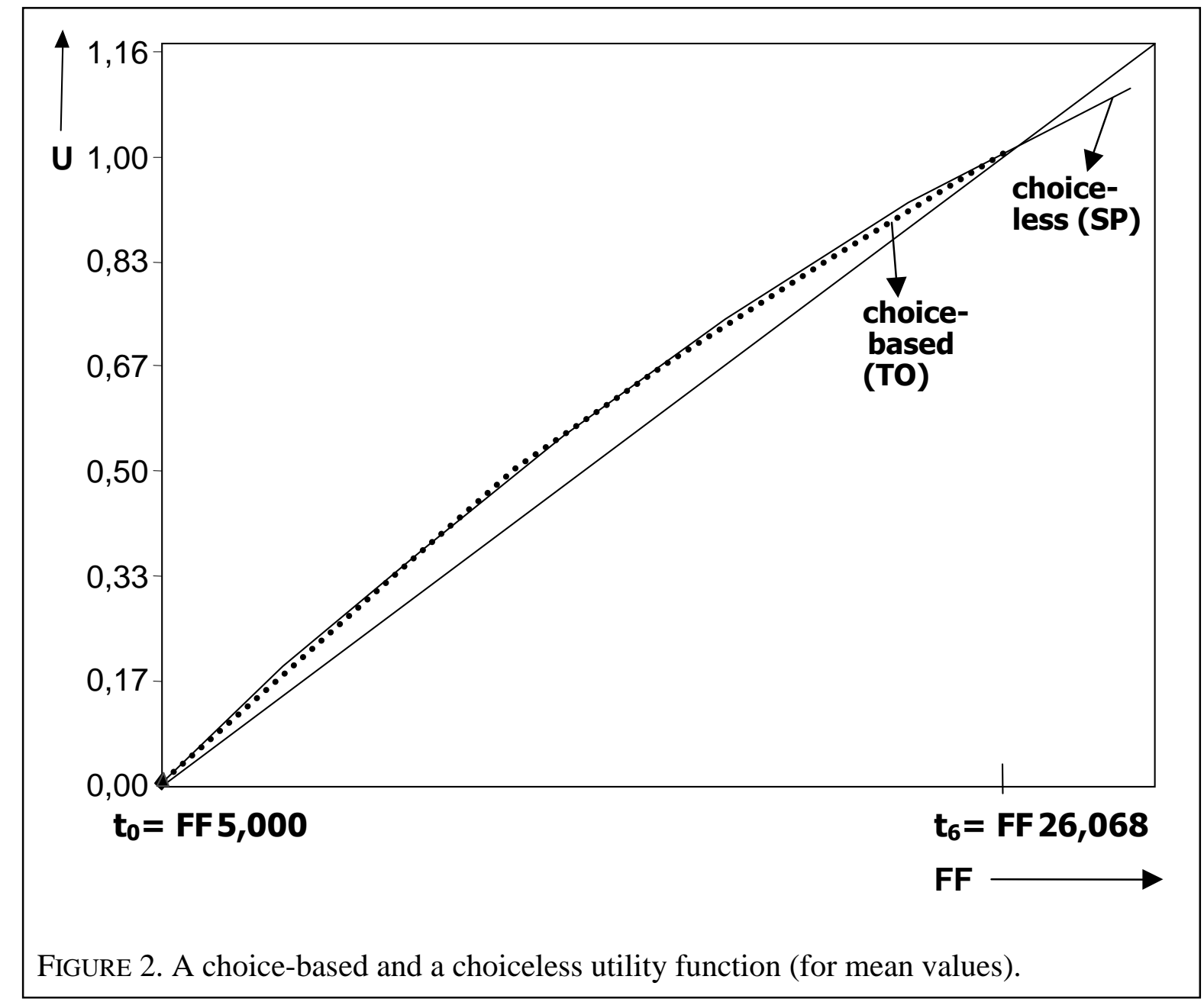


411 Results. The mean values of the variables $\mathrm{t}_{\mathrm{i}}$ and $\mathrm{s}_{\mathrm{i}}$ are depicted in the TO and SP 412 curves in Figure 2, which were obtained through linear interpolation. Numerical 413 details are in Table 1 in Appendix B. The curves, based on averages, can be 414 interpreted as the utility functions of a representative agent. The figure suggests that 415 the choice-based and choiceless utility curves are the same. This suggestion is 416 confirmed by statistical analyses.

$417 \quad$ For each $\mathrm{j}$ we have $\mathrm{s}_{\mathrm{j}}=\mathrm{t}_{\mathrm{j}}$ under $\mathrm{H}_{0}$ because both should then have utility $\mathrm{j} / 6$ (Eqs. 4185.1 and 5.2). $\mathrm{H}_{0}$ is rejected for no $\mathrm{j}$, with $\mathrm{p}$-values ranging from .118 to .211. The 419 equality is confirmed by parametric fittings, depicted in the upper two panels of 420 Figure 4 and analyzed in Appendix D.

421 Linearity of the TO- and SP utility curves in Figure 2 was tested through

422 Friedman tests, and was rejected for both TO and SP $\left(\mathrm{H}_{0}\right.$ for TO: $\mathrm{t}_{\mathrm{j}-1}-\mathrm{t}_{\mathrm{j}}$ is

423 independent of $\mathrm{j}, \chi_{5}^{2}=29.6, \mathrm{p}<.001 ; \mathrm{H}_{0}$ for SP is similar, $\left.\chi_{5}^{2}=38.05, \mathrm{p}<.001\right)$. It

424 was also rejected by the parametric analyses in Appendix D.

Psychological explanation for the equality of choiceless SP utilities and choice-based

427 TO utilities. Under expected utility, the risky utility function was traditionally

428 distinguished from riskless concepts because the former should comprise all aspects

429 of risk attitudes, which obviously play no role for the latter concepts. Under prospect

430 theory, aspects of risk attitudes beyond the utility of outcomes can be modeled

431 through probability weighting (and loss aversion for negative outcomes). It then

432 becomes conceivable, at least as an empirical hypothesis to be tested, that the utility 433 function of prospect theory agrees with riskless concepts.

434 From a psychological perspective, it is not surprising that the choice-based and 435 choiceless utilities measured in this paper agree, because the TO method appeals to a 436 perception of preference in an indirect manner: In the indifference $\left(1 / 3, t_{i} ; r\right) \sim\left(1 / 3, t_{i-1}\right.$; $437 \mathrm{R}$ ), a perceived strength of preference between $t_{i}$ and $t_{i-1}$, associated with probability $4381 / 3$, offsets the same counterargument of receiving $\mathrm{R}$ instead of $r$, associated with 439 probability $2 / 3$, for each $i$. Because the relevant probabilities are the same for each $i$, 440 it is plausible that the perceived strength of preference between $t_{i}$ and $t_{i-1}$ is the same 441 for each i (Wakker \& Deneffe 1996). In this way, it is not surprising that the TO and 442 SP methods gave similar results. 
444

445

446

447

448

449

450

451

452

453

454

455

456

457

458

459

460

461

462

463

464

465

466

467

468

469

470

471

472

473

474

475

476

\section{Verifying the Validity of Measurements}

A pessimistic interpretation of the equality found in the preceding section can be devised, in agreement with the constructive view of preference (Gregory,

Lichtenstein, \& Slovic 1993; Loomes, Starmer, \& Sugden 2003): The participants may simply have used similar heuristics in both methods used, and their TO answers may not reflect genuine preference. To investigate this possibility, we used a third, traditional, method for measuring utility, a certainty-equivalent method. For the first 13 participants, only TO and SP measurements were conducted. Then it was realized that further questions were feasible. Therefore, for the remaining 34 participants not only TO and SP measurements, but also two certainty equivalent measurements were conducted.

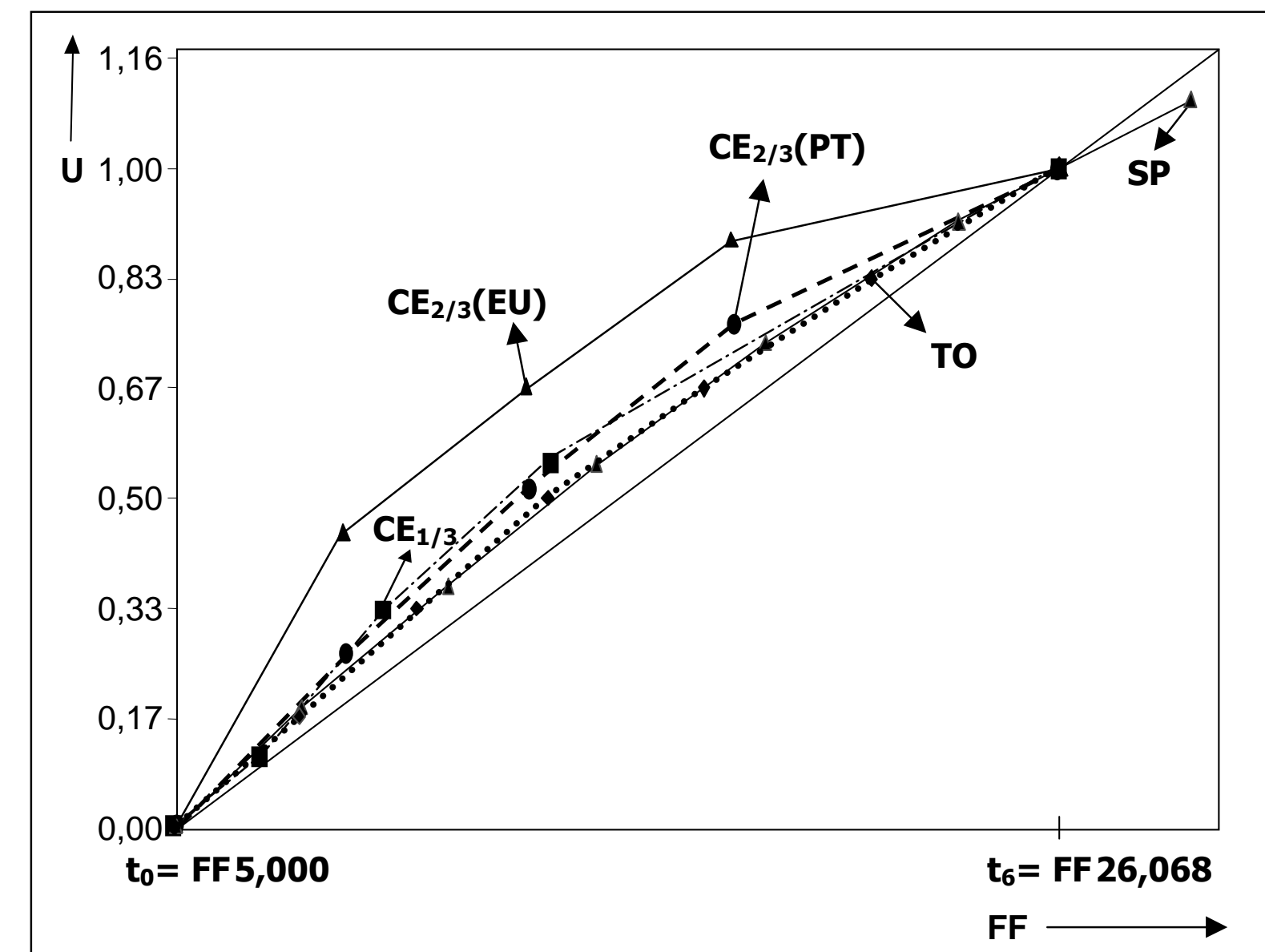

FIGURE 3. All utility functions (for mean values).

Certainty-equivalent methods compare sure amounts of money to two-outcome prospects and have been used in many studies (von Winterfeldt \& Edwards 1986). 
477 They have a format different than TO and SP methods. Therefore, if heuristics are

478

479

480

481

482

483

484

485 used, it is plausible that they will be different for certainty equivalents than for the TO and SP methods, and that they will not generate the same utilities. The third method considered prospects that assign probability $1 / 3$ to the best outcome. The reason for this particular choice of probability will be explained at the end of this section. The third method is called the $C E_{1 / 3}$ method. Amounts $\mathrm{c}_{2}, \mathrm{c}_{1}$, and $\mathrm{c}_{3}$ were elicited such that $\mathrm{c}_{2} \sim\left(1 / 3, \mathrm{t}_{6} ; \mathrm{t}_{0}\right), \mathrm{c}_{1} \sim\left(1 / 3, \mathrm{c}_{2} ; \mathrm{t}_{0}\right)$, and $\mathrm{c}_{3} \sim\left(1 / 3, \mathrm{t}_{6} ; \mathrm{c}_{2}\right)$.

We first analyze this method in the classical manner, i.e., assuming EU. We will see later that the following equalities and analysis remain valid under prospect theory. With $\mathrm{U}\left(\mathrm{t}_{0}\right)=0$ and $\mathrm{U}\left(\mathrm{t}_{6}\right)=1$, we get:

$$
\mathrm{U}\left(\mathrm{c}_{2}\right)=\frac{1}{3}, \mathrm{U}\left(\mathrm{c}_{1}\right)=\frac{1}{9} \text {, and } \mathrm{U}\left(\mathrm{c}_{3}\right)=\frac{5}{9} \text {. }
$$

All nonparametric utility curves measured in our experiment, based on group averages and linear interpolation, are assembled in Figure 3. Figure 4 gives the average result of parametric fittings, explained in Appendix C. The figures suggest that the average utility function resulting from the $\mathrm{CE}_{1 / 3}$ observations agrees well with the TO and SP utility functions. Analysis of variance with repeated measures for the parametric fittings confirms the equality of the $\mathrm{TO}, \mathrm{SP}$, and $\mathrm{CE}_{1 / 3}$ measurements while taking into account differences at the individual level, with $\mathrm{F}(2,66)=0.54, \mathrm{p}=0.58$. The same conclusion follows from other statistical analyses reported in Appendices B and D.

At this point, two concerns can be raised. First, it may be argued that the assumption of EU used in the preceding analysis is not descriptively valid. Second, it may be conjectured that our design does not have the statistical power to detect differences (apart from nonlinearity of the utility curves). To investigate these concerns, we used a fourth method for measuring utility, another certainty-equivalent method. This method considered prospects that assign probability $2 / 3$ to the best outcome and is, therefore, called the $C E_{2 / 3}$ method. The same 34 individuals participated as in the $C E_{1 / 3}$ method. Amounts $d_{2}, d_{1}$, and $d_{3}$ were elicited such that $d_{2}$ $\sim\left(2 / 3, \mathrm{t}_{6} ; \mathrm{t}_{0}\right), \mathrm{d}_{1} \sim\left(2 / 3, \mathrm{~d}_{2} ; \mathrm{t}_{0}\right)$, and $\mathrm{d}_{3} \sim\left(2 / 3, \mathrm{t}_{6} ; \mathrm{d}_{2}\right)$. We first analyze this method assuming EU. With $\mathrm{U}\left(\mathrm{t}_{0}\right)=0$ and $\mathrm{U}\left(\mathrm{t}_{6}\right)=1$, the following equalities are implied.

$$
\mathrm{U}\left(\mathrm{d}_{1}\right)=\frac{4}{9}, \mathrm{U}\left(\mathrm{d}_{2}\right)=\frac{2}{3}, \text { and } \mathrm{U}\left(\mathrm{d}_{3}\right)=\frac{8}{9}
$$


508

509

510

511

512

513

514

515

516

517

518

519

520

521

522

523

524

525

526

527

528

529

530

531

532

533

534

The average utility function resulting from the $\mathrm{CE}_{2 / 3}$ observations under $\mathrm{EU}$ is depicted as the $\mathrm{CE}_{2 / 3}(\mathrm{EU})$ curve in Figure 3 for linear interpolation, and in the middle right panel in Figure 4. The function strongly deviates from the other curves.

Whereas analysis of variance with repeated measures for the parametric fittings concluded that the three measurements (TO, SP, $\mathrm{CE}_{1 / 3}$ ) are the same, addition of $\mathrm{CE}_{2 / 3}(\mathrm{EU})$ leads to the conclusion that the four measurements (TO, SP, $\mathrm{CE}_{1 / 3}$, $\left.\mathrm{CE}_{2 / 3}(\mathrm{EU})\right)$ are not the same, $\mathrm{F}(3,99)=6.39, \mathrm{p}=0.001$. That $\mathrm{CE}_{2 / 3}(\mathrm{EU})$ is different from the other measurements, is confirmed by other statistical analyses, such as pairwise comparisons, presented in Appendices B and D. This finding falsifies EU and agrees with the EU violations documented in the literature.

We reanalyze the results of the certainty-equivalent methods by means of prospect theory, and correct the utility measurements for probability weighting. Such corrections were suggested before by Fellner (1961, p. 676), Wakker \& Stiggelbout (1995), Stalmeier \& Bezembinder (1999), and Bleichrodt, Pinto, \& Wakker (2001). We assume the probability weighting function of Figure 1 for all individuals. This assumption obviously is an approximation because in reality the probability weighting function will depend on the individual. The descriptive performance of prospect theory could be improved if information about individual probability weighting were available. In the absence of such information, we expect that, on average, PT with the probability weighting function of Figure 1 will yield better results than EU, which also assumes that the weighting function is the same for all individuals but, furthermore, assumes that it is linear. Let us repeat that the analysis of the TO method remains valid under PT, irrespective of the individual probability weighting functions. Therefore, contrary to the CE methods, it is not affected by individual variations in probability weighting. 
534

535

536

537

538

539

540

541

542

543

544

545

546

547

548

549

550

551

552

553

554

555

556

557

558

559

560

561

562

563

564

565
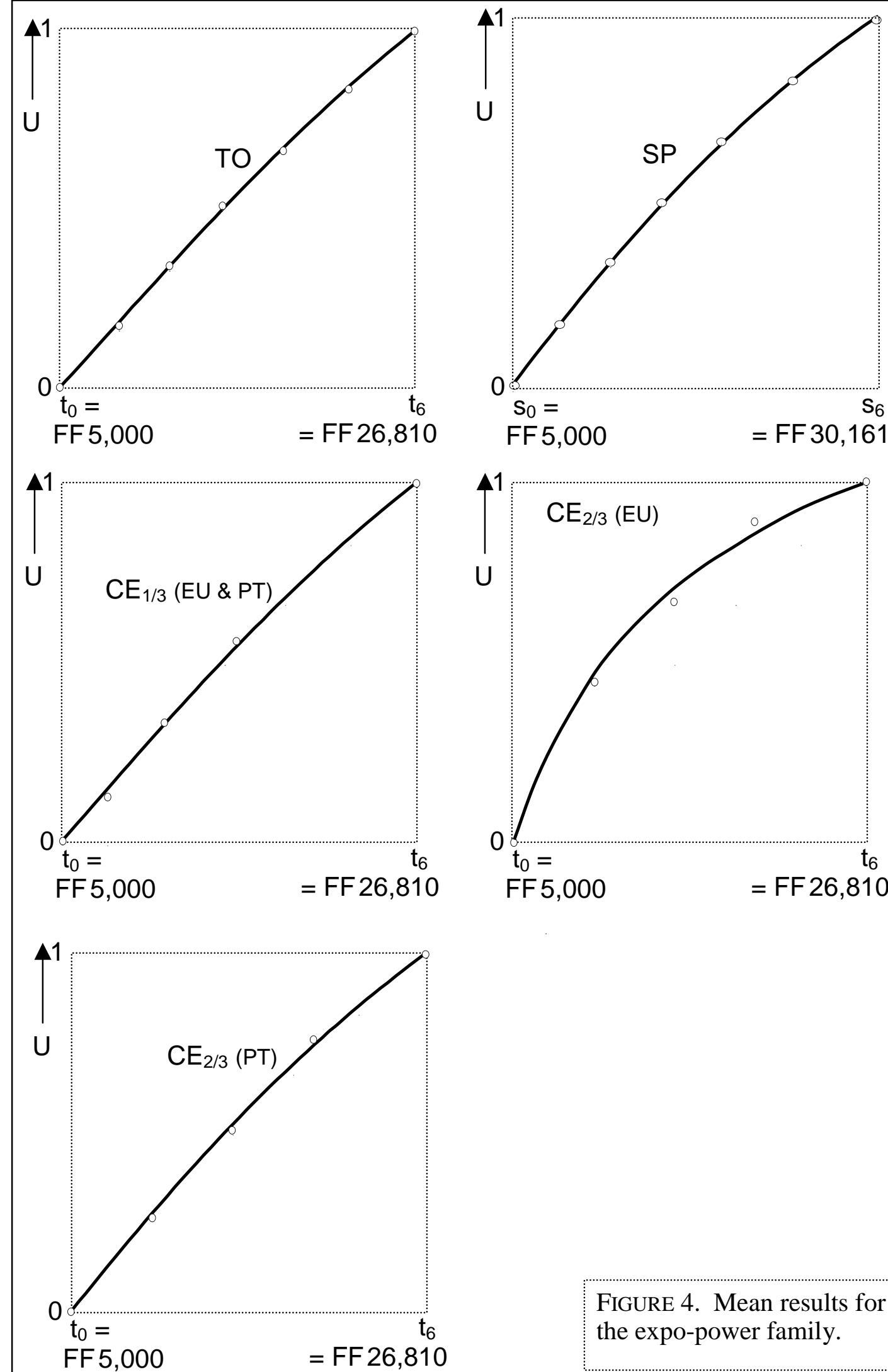

FIGURE 4. Mean results for the expo-power family. 
It has been found that, on average, w(1/3) is approximately $1 / 3$ (see Figure 1).

568 Therefore, our analysis of $\mathrm{CE}_{1 / 3}$ needs no modification and Eq. 6.1 and the utility

569 function depicted in Figure 1 remain valid under PT. Accordingly, the agreement

570 between the $\mathrm{CE}_{1 / 3}$ utilities and the $\mathrm{TO}$ utilities also remains valid. It has been found

571 that $\mathrm{w}(2 / 3)$ is approximately .51 (see the references given at Figure 1). Hence, the

572 analysis of $\mathrm{CE}_{2 / 3}$ that was based on EU needs modification. We now find

$573 \quad \mathrm{U}\left(\mathrm{d}_{1}\right)=0.26, \mathrm{U}\left(\mathrm{d}_{2}\right)=0.51$, and $\mathrm{U}\left(\mathrm{d}_{3}\right)=0.76$

574 instead of Eq. 6.2. The resulting corrected utility curves, denoted $\mathrm{CE}_{2 / 3}(\mathrm{PT})$, are

575 depicted in Figures 3 and 4. They agree well with the TO, SP, and $\mathrm{CE}_{1 / 3}$ curves.

576 Analysis of variance with repeated measures for the parametric fittings confirms the

577 equality of the TO, $\mathrm{SP}, \mathrm{CE}_{1 / 3}$, and $\mathrm{CE}_{2 / 3}(\mathrm{PT})$ measurements, with $\mathrm{F}(3,99)=0.63, \mathrm{p}=$

578 0.6. In other words, replacing $\mathrm{CE}_{2 / 3}(\mathrm{EU})$ by $\mathrm{CE}_{2 / 3}(\mathrm{PT})$ restores the equality of utility.

579 The equality is confirmed by other statistical analyses, reported in Appendices B and

580 D.

\section{Discussion}

The statistical analyses suggested that the $\mathrm{TO},(\mathrm{SP}), \mathrm{CE}_{1 / 3}$, and $\mathrm{CE}_{2 / 3}(\mathrm{PT})$ utilities are the same, but that $\mathrm{CE}_{2 / 3}(\mathrm{EU})$ gives different values. According to PT, the discrepancy between the $\mathrm{CE}_{2 / 3}$ utilities, derived under $\mathrm{EU}$, and the other utilities found, is caused by violations of EU. After correction for these violations, a reconciliation of the different risky utility measurements, $\mathrm{TO}, \mathrm{CE}_{1 / 3}$, and $\mathrm{CE}_{2 / 3}$, results. The reconciliation suggests one consistent cardinal index of utility for risk, supporting the results of the TO measurements indeed. It entails a positive result within the revealed-preference paradigm. The further agreement of this index with the SP index extends beyond the domain of revealed preference, and is the main message of this paper.

The role of real incentives has often been debated, and their importance is now generally acknowledged (Binmore 1999; Smith 1982). Real incentives are commonly

596 interest only for significant amounts of money, for two reasons. First, important decisions typically involve large amounts of money and, second, utility is close to 
598 linear for moderate amounts so that no measurement is needed there (Marshall 1890; Rabin 2000; Savage 1954 p. 60). For these reasons, we had to use significant amounts and could not implement real incentives.

Camerer \& Hogarth (1999) and Hertwig \& Ortmann (2001) surveyed the role of real incentives. Real incentives improve performance in cognitively demanding tasks such as predicting company bond ratings (Camerer \& Hogarth 1999, Table 1). Real incentives reduce variance and increase general risk aversion but do not affect results otherwise for simple tasks such as choices between simple prospects, the topic of this paper. Kachelmeier \& Shehata (1992) confirmed this claim for high stakes. Some studies have reported negative effects of real incentives upon intrinsic motivations (Frey \& Oberholzer-Gee 1997; Gneezy \& Rustichini 2000; Loewenstein 1999 Section 5). In summary, because real incentives do not have much impact on choices in the domain of our study, we have carried out this investigation even though real incentives could not be implemented. The utility function for money is central in economics and its experimental measurement deserves investigation (Stigler 1950 Section IV.c), even if a resort to hypothetical choices cannot be avoided (Shafir, Diamond, \& Tversky 1997, p. 350).

We used two other utility measurement methods not reported here, an unchained certainty equivalent method where we elicited values $x_{j}$ equivalent to $\left(j / 6, t_{6} ; t_{0}\right)$, and a lottery equivalent method (McCord \& de Neufville 1986) where we elicited probabilities $\mathrm{q}_{\mathrm{j}}$ to give equivalences $\left(\mathrm{q}_{\mathrm{j}}, \mathrm{t}_{\mathrm{j}} ; \mathrm{t}_{0}\right) \sim\left(0.75, \mathrm{t}_{6} ; \mathrm{t}_{0}\right), \mathrm{j}=1, \ldots, 5$. The former method gave the same results as the methods reported in this paper, with utilities diverging significantly from $\mathrm{TO}, \mathrm{CE}_{1 / 3}, \ldots$ etc. under expected utility, but convergence re-established under prospect theory. Under the lottery equivalent method, there was partial divergence from TO etc. under expected utility, but prospect theory did not improve the case and even enlarged the divergence. The results of the lottery equivalent method may be explained by a bias upward due to scale compatibility that has been found to bias probability matching questions (Bleichrodt 2002). The data of the two methods discussed here were noisier than those of the other methods, and these two methods have not been widely used in the literature. Therefore, we do not report their details. They are available in Barrios (2003).

We next compare our findings to existing empirical findings in the literature, beginning with studies of choice-based utilities. For this context, there have been several studies that found results similar to ours. Karmarkar (1978) and McCord \& de 
632 Neufville (1986) found that utilities, measured through certainty equivalents with 633 different probabilities, are inconsistent when analyzed by means of EU. Abdellaoui 634 (2000) found that the utilities measured by the TO method are not affected by 635 probability weighting. Bleichrodt, Pinto, \& Wakker (2001) found that corrections by 636 means of the probability weighting function of Figure 1 reconcile discrepancies 637 between choice-based utilities. Tversky \& Fox (1995 p. 276) pointed out the 638 appealing feature of the $1 / 3$ probability that it does not lead to systematic probability 639 transformations in CE questions. Finally, Rabin (2000) argued on theoretical grounds 640 that utility is more linear than commonly thought, and that most of the commonly 641 observed risk aversion is due to factors other than utility curvature.

642 Rabin's argument is based on a paradox entailing that, if risk attitude is based 643 solely on utility curvature as in expected utility, then a moderate and realistic degree 644 of risk aversion for moderate stakes necessarily implies an extreme and unrealistic 645 degree of risk aversion for high stakes. We used prospect theory, where risk attitude 646 consists of other factors besides utility curvature, to estimate the utility function. Our 647 empirical findings of moderate utility curvature confirm Rabin's predictions. Our 648 contribution to Rabin's paradox is to demonstrate that not only does it refute expected 649 utility, but also it can be accommodated by prospect theory.

650 For the economic literature, the novelty of our study lies in the comparison of 651 choice-based utilities, derived from prospect theory, with choiceless utilities derived 652 from strength-of-preference judgments. The direct agreement between these 653 measurements (alluded to by Camerer 1995, p. 625) is remarkable. Our 654 measurements satisfy Birnbaum \& Sutton's (1992) principle of scale convergence, 655 according to which different ways to measure utility should give the same result. It 656 would, indeed, be desirable if one concept of utility could emerge that is relevant for 657 many contexts, such as decision under risk, welfare evaluations, intertemporal 658 discounted utility, case-based reasonings (Gilboa \& Schmeidler 1995), etc. (cf. 659 Broome's 1991 index of goodness, or Robson 2001).

660 In applied domains, e.g. in health economics, it is common practice to use 661 utilities measured in one context for applications in other contexts (Gold et al. 1996; 662 Torrance, Boyle, \& Horwood 1982). For example, risky utilities measured through 663 the "standard gamble method" have been used in policy decisions about interpersonal 664 tradeoffs (treating elderly versus young people) or intertemporal decisions (current 665 prevention measures against future health impairments). Also choiceless utilities, 
666 measured through direct scaling questions or otherwise, have been used for decision 667 making. The pragmatic justification is that no better data are available, and decisions 668 have to be taken as good as possible with whatever is available. Empirical relations 669 between various utilities have been studied extensively. See Frey \& Stutzer (2000 p. 670 920), Pennings \& Smidts (2000), Revicki \& Kaplan (1993), Robinson, Loomes, \& 671 Jones-Lee (2001). Our improved procedures based on prospect theory provide a new 672 way of studying such relationships.

673 We only compared risky choice-based utilities to riskless choiceless utilities 674 derived from strengths of preferences, and we did not consider utilities derived from 675 other tradeoffs such as interpersonal or intertemporal. We hope that future empirical 676 studies will consider such other tradeoffs, and that Birnbaum and Broome's scale 677 convergence can be established with one unified concept of utility relevant to many 678 domains in social sciences. Then the use of choiceless data in applications, such as 679 health economics, can become more acceptable to mainstream economists and 680 ordinalists, not only for pragmatic reasons (Manski 2004), but also conceptually.

\section{Conclusion}

683 In the classical economic debate between cardinalists and ordinalists, the latter 684 assumed that direct judgments, having no preference basis, are not meaningful. In the 685 light of today's advances in experimental methods in economics, the question whether 686 relations exist between direct judgments and preferences can be investigated 687 empirically. The first investigations of such relations were conducted in decision 688 theory. These investigations assumed expected utility theory, so that their results were distorted by the descriptive deficiencies of this theory. Prospect theory provided

690 descriptive improvements. Using this theory, our experiment suggests a simple 691 relation between direct strength-of-preference judgments and risky-decision utilities. 692 If an empirical relationship between direct judgments and preferences can be 693 firmly established, then direct judgments will provide useful data for economic 694 analyses in contexts where preferences are hard to measure because of choice 695 anomalies (Kahneman 1994). Conversely, such links provide a consistency basis for 696 direct judgments. The result will be that direct judgments reinforce the revealed 697 preference approach and vice versa. We, therefore, hope for further empirical 698 investigations of the relations between direct judgments and revealed preferences. 


\section{Appendix A. A Two-Step Procedure for Eliciting Indifferences}

701 This appendix describes the new two-step procedure that was developed so as to obtain

702 reliable indifferences. We first consider the measurement of $t_{1}$ for the TO method. That

703 is, a value $x\left(=t_{1}\right)$ was to be found to yield an indifference $A=(1 / 3,5000 ; 2000)$

$704(1 / 3, \mathrm{x} ; 1000)=\mathrm{B}$. Figure 5 displays these prospects (called propositions there) for $\mathrm{x}=$

705 11000. The first step of our procedure established an interval containing $\mathrm{t}_{1}$. It started

706 with $\mathrm{x}=5000$, which clearly is a lowerbound for $\mathrm{t}_{1}$ because the right prospect $\mathrm{B}$ then is

707 dominated by the left prospect A. By means of a scrollbar, the experimenter next

708 increased $\mathrm{x}$ to 25000 , and here all participants preferred the right prospect $\mathrm{B}$, so that

70925000 is an upper bound for $\mathrm{t}_{1}$ for all participants. These questions, yielding a

710 preliminary interval $[5000,25000]$ containing $\mathrm{t}_{1}$, served only to familiarize the subjects

711 with the choices. The interval containing $\mathrm{t}_{1}$ that we searched for was to be a narrower

712 subinterval of [5000, 25000], and was obtained as follows.

713 The scrollbar was again placed at its initial value $\mathrm{x}=5000$, where $\mathrm{B}$ is dominated

714 by $\mathrm{A}$. The experimenter increased $\mathrm{x}$ until the participant was no longer sure that she

715 prefers A. Next a smaller outcome $\mathrm{x}$ was found for which the participant was still sure

716 to prefer A to B, say $\mathrm{x}=\alpha>5000$. Similarly, an outcome $\mathrm{x}$ of $\mathrm{B}$ was found for which

717 the participant was sure to prefer $\mathrm{B}$ to $\mathrm{A}$, say $\mathrm{x}=\beta<25000$. Obviously, $\beta>\alpha$; if not,

718 the participant did not understand the procedure and it was repeated. Thus, an interval

$719[\alpha, \beta]$ was obtained that contained the indifference value $t_{1}$. We wanted this interval to

720 be of the same length for all participants. Hence, we asked participants to be more

721 precise if their interval $[\alpha, \beta]$ was too long. Commonly it was shorter, in which case the

722 computer automatically enlarged it. In this manner, an interval of a fixed length was

723 obtained for the second step. Figure 5 displays the final result of Step 1 for a participant

724 with $[\alpha, \beta]=[7000,11000]$ as the interval of fixed length containing $\mathrm{t}_{1}$. 

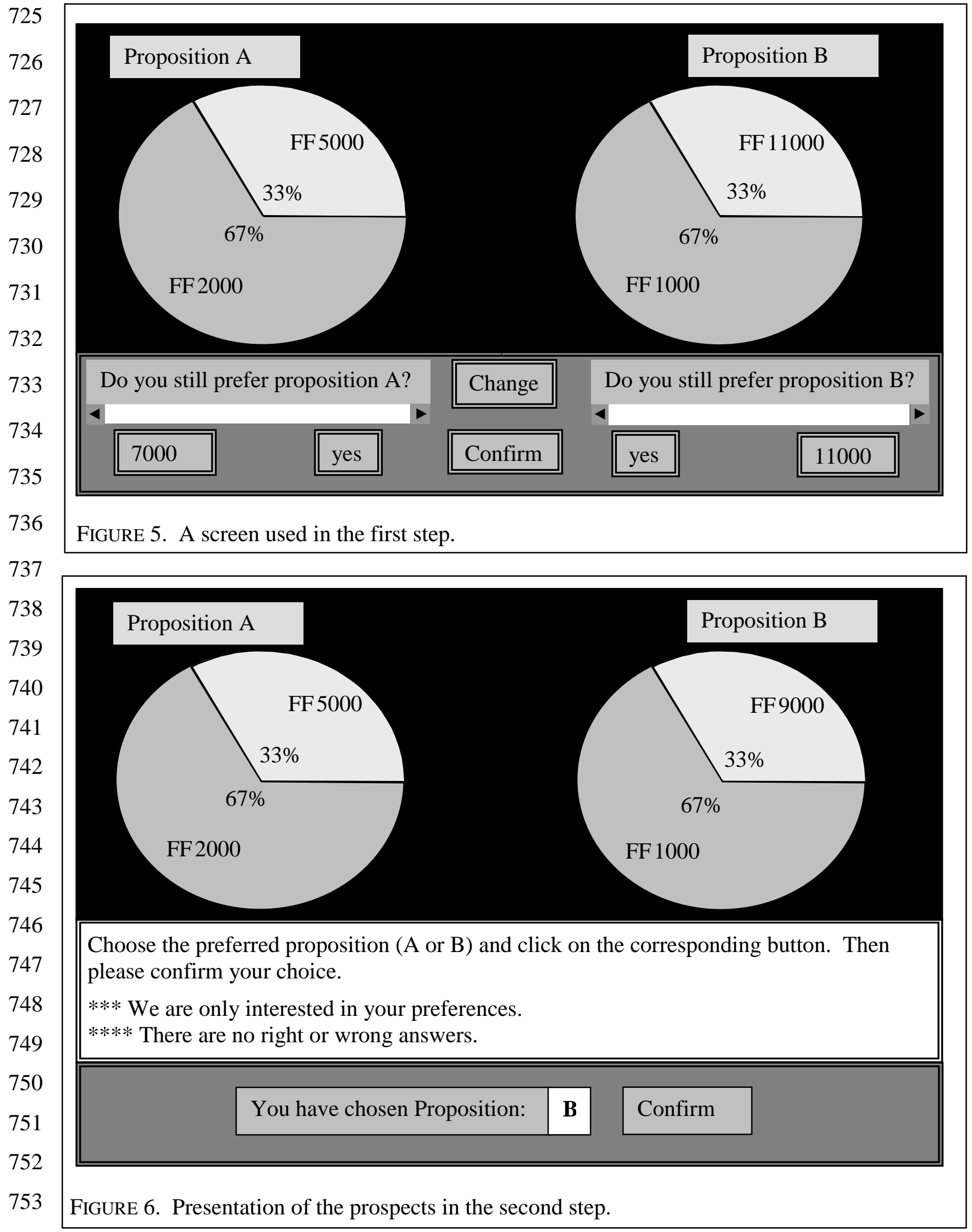
In Step 2 of our procedure to elicit $t_{1}$, a choice-based bisection procedure was

757

758

759

760

761

762

763

764

765

766

767

768

769

770

771

772

773

774

775

776

777

778

779

780

781

782

783

used to find the indifference value $x=t_{1} \in[\alpha, \beta]$; see Figure 6. The midpoint $(\alpha+\beta) / 2$

of the interval of Step 1 was substituted for $\mathrm{x}$, and the participant was asked to choose

between the prospects-indifference was not permitted. The midpoint was

subsequently combined with the left or right endpoint of the preceding interval,

depending on the preference expressed. In this manner, a new interval resulted that

contained $t_{1}$ and that was half as large as the preceding interval. After five similar

iterations, the interval was sufficiently narrow and its midpoint was taken as $t_{1}$. To

test for consistency, we repeated the choice of the third iteration; it was virtually

always ( $\geq 92 \%$ for each measurement) consistent in our experiment.

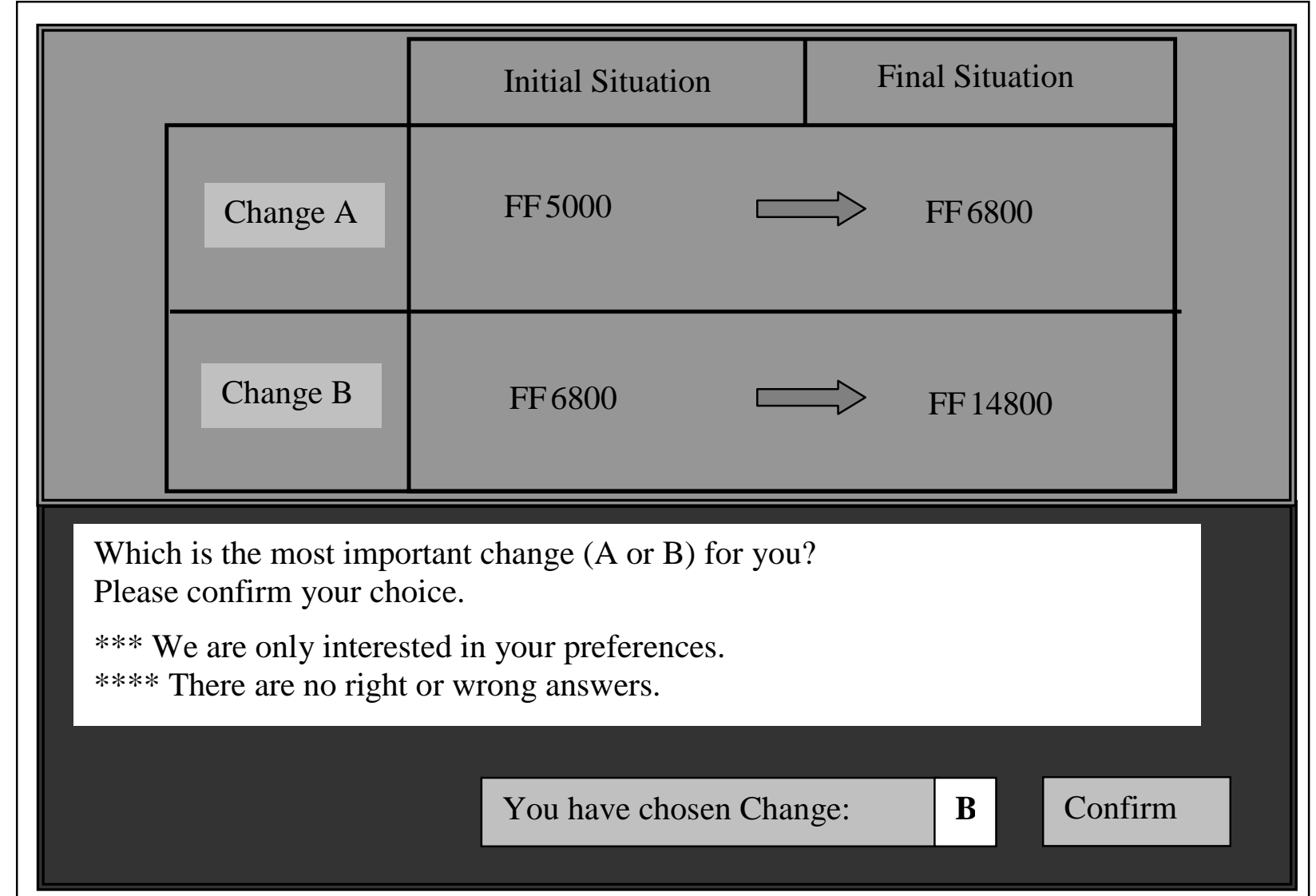

FIGURE 7. Presentation of strength of preference questions. 


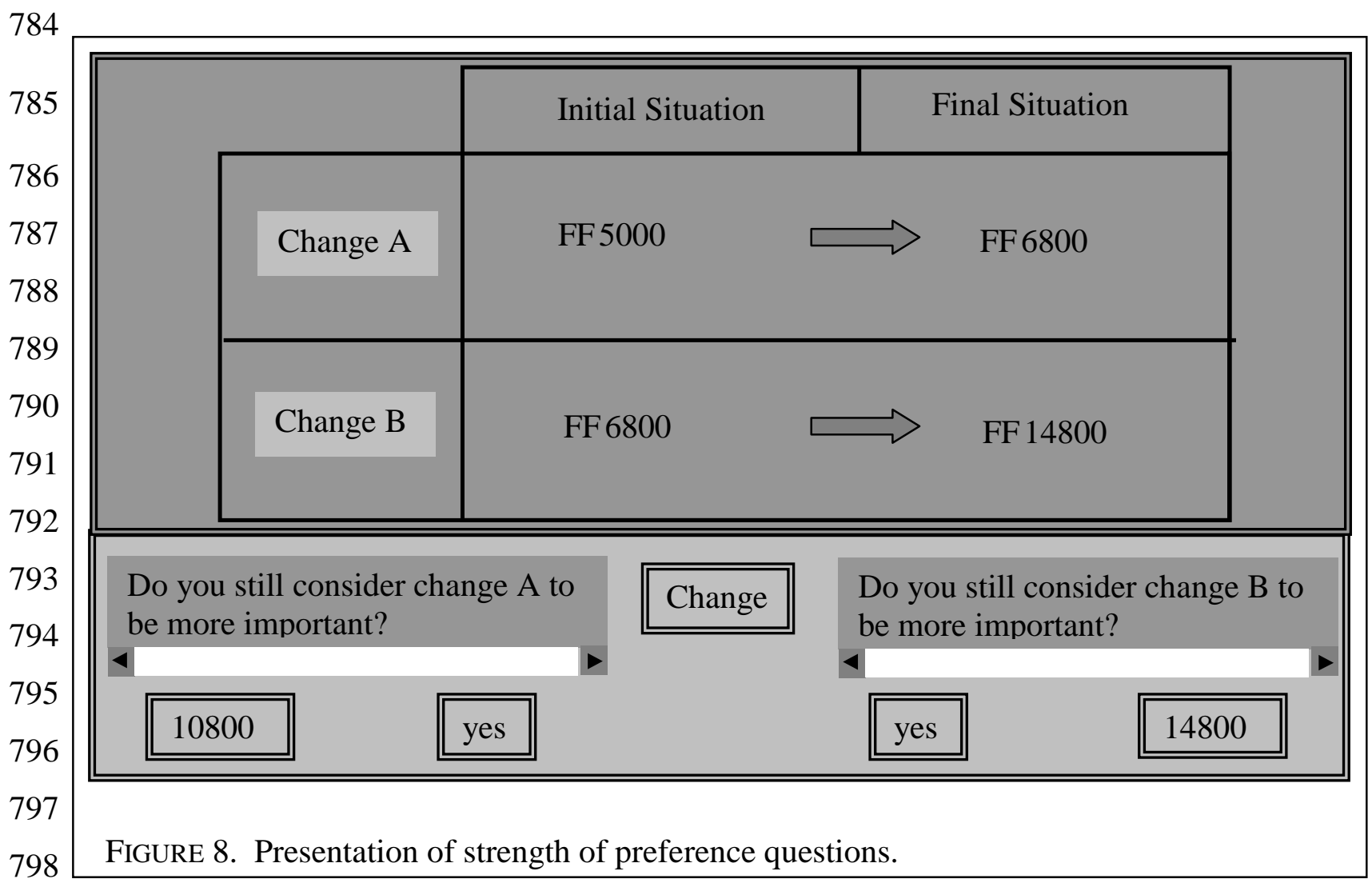

799

800

We adopted the above elaborate method of eliciting indifference values so as to

801 obtain high-quality data, avoiding many biases that have been known to arise from

802 direct matching questions (Bostic, Herrnstein, \& Luce 1990). The indifference values

$803 \mathrm{t}_{2}, \ldots, \mathrm{t}_{6}$ were elicited similarly. For the CE measurements we used the same way to

804 elicit indifferences as for the TO measurements, now with one option being riskless.

805 For the strength-of-preference measurements, a similar two-stage procedure was used

806 but the stimuli were different because no prospects were involved. Figures 7 and 8

807 show the screens presented to the participants in the two stages.

808

809 Appendix B. Statistical Analysis of Raw Data

810 Table 1 gives descriptive statistics of our measurements. Paired t-tests of the

811 equality of TO and SP measurements were described in the main text. We next

812 consider paired $t$-test comparisons of the other two measurements with TO. 
814 TABLE 1. Mean values in French francs. Standard deviations are in parentheses.

\begin{tabular}{llllll}
\hline $\mathrm{i}$ & \multicolumn{1}{c}{$\mathrm{t}_{\mathrm{i}}$} & \multicolumn{1}{c}{$\mathrm{s}_{\mathrm{i}}$} & \multicolumn{1}{c}{$\mathrm{c}_{\mathrm{i}}$} & $\mathrm{d}_{\mathrm{i}}$ \\
\hline 0 & $5000(0)$ & $5000(0)$ & & & \\
1 & $8048(1318)$ & $8048(1318)$ & $7047(1055)$ & $8976(1964)$ \\
2 & $11002(3022)$ & $11482(3067)$ & $10011(2201)$ & $13329(3754)$ \\
3 & $14244(5332)$ & $15076(4932)$ & $13979(4214)$ & $18205(7338)$ \\
4 & $18023(7864)$ & $19268(7275)$ & & & \\
5 & $22165(11076)$ & $24210(10285)$ & & & \\
6 & $26810(14777)$ & $30161(14644)$ & & & \\
\hline
\end{tabular}

815

816

817

818

819

820

821

822

823

824

825

826

827

828

829

831

832

833

$830 \mathrm{CE}_{2 / 3}$-values, predicted by EU, are strongly rejected. If we reanalyze the data through

834 TABLE 2. Direct tests of the consistency of choice-based methods.

To compare $\mathrm{TO}$ with $\mathrm{CE}_{1 / 3}$, note that $\mathrm{c}_{2}=\mathrm{t}_{2}$ under $\mathrm{H}_{0}$ because both should have utility $1 / 3$ (Eqs. 5.1 and 6.1). Further comparisons between c- and t-values cannot be made directly because the observations concern different points in the domain. To nevertheless obtain comparisons, we use linear interpolations. (Other parametric fittings will be the topic of Appendix B.) Linear interpolation is best done on the scale with most observations, i.e. the TO scale. For example, if $U\left(t_{0}\right)=0$ and $U\left(t_{1}\right)=$ $1 / 6$ (Eq. 5.1) then, by linear interpolation, $\mathrm{U}\left(2 / 3 \mathrm{t}_{1}+1 / 3 \mathrm{t}_{0}\right) \approx 1 / 9$ and $2 / 3 \mathrm{t}_{1}+1 / 3 \mathrm{t}_{0}$ can be compared to $c_{1}$ (Eq. 5.2). As indicated in the fourth row of Table 2, $2 / 3 t_{4}+1 / 3 t_{3}$ can similarly be compared to $c_{3}$. The $t_{33^{-}}$and $\mathrm{p}$-values in the table indicate that no equality of the c-values and the corresponding (interpolations of) t-values is rejected statistically.

For the comparison of the $\mathrm{CE}_{2 / 3}$ measurements with $\mathrm{TO}$, note that $\mathrm{d}_{2}=\mathrm{t}_{4}$ under $\mathrm{H}_{0}$, because both should have utility $2 / 3$ (Eqs. 5.1 and 6.2). Further comparisons require linear interpolations, indicated in Table 2. All equalities between TO- and

831 PT, and adapt the linear interpolations correspondingly as indicated in the table, then 832 the equality of utility is re-established. 


\begin{tabular}{llllll}
\hline theory & CEs & Utility & TOs $*$ & $t_{33}$ & p-value \\
\hline EU \& PT & $\mathrm{c}_{1}$ & $1 / 9$ & $2 / 3 \mathrm{t}_{1}+1 / 3 \mathrm{t}_{0}$ & 0.09 & .928 \\
EU\& PT & $\mathrm{c}_{2}$ & $1 / 3$ & $\mathrm{t}_{2}$ & -1.49 & .146 \\
EU\& PT & $\mathrm{c}_{3}$ & $5 / 9$ & $1 / 3 \mathrm{t}_{4}+2 / 3 \mathrm{t}_{3}$ & -1.52 & .138 \\
\hline EU & $\mathrm{d}_{1}$ & $4 / 9$ & $2 / 3 \mathrm{t}_{3}+1 / 3 \mathrm{t}_{2}$ & -5.41 & .000 \\
EU & $\mathrm{d}_{2}$ & $2 / 3$ & $\mathrm{t}_{4}$ & -4.30 & $\mathbf{. 0 0 0}$ \\
EU & $\mathrm{d}_{3}$ & $8 / 9$ & $1 / 3 \mathrm{t}_{6}+2 / 3 \mathrm{t}_{5}$ & -3.96 &. $\mathbf{0 0 0}$ \\
$\mathrm{PT}$ & $\mathrm{d}_{1}$ & 0.26 & $.58 \mathrm{t}_{2}+.42 \mathrm{t}_{1}$ & -1.45 & .158 \\
$\mathrm{PT}$ & $\mathrm{d}_{2}$ & 0.51 & $.08 \mathrm{t}_{4}+.92 \mathrm{t}_{3}$ & -1.19 & .244 \\
$\mathrm{PT}$ & $\mathrm{d}_{3}$ & 0.76 & $.58 \mathrm{t}_{5}+.42 \mathrm{t}_{4}$ & -1.78 & .084 \\
\hline
\end{tabular}

*: interpolated $\mathrm{t}_{\mathrm{i}}$ 's

All tests in this appendix confirm the conclusions based on analysis of variance with repeated measures, reported in the main text. Nevertheless, a number of

839 objections can be raised against the analyses of this appendix. For the scale that is 840 interpolated, a bias downward is generated because utility is usually concave and not

841 linear. For scales with few observations such as the CE scales, the bias can be big 842 and, therefore, a direct comparison of $\mathrm{CE}_{1 / 3}$ and $\mathrm{CE}_{2 / 3}$ is not well possible. The latter 843 problem is aggrevated because the different CE measurements focus on different parts 844 of the domain.

845 The pairwise comparisons of the different points in Table 2 are not independent 846 because the measurements are chained. Biases in measurements may propagate. This 847 may explain why all five $\mathrm{s}_{\mathrm{j}}$ values in Table 1 exceed the corresponding $\mathrm{t}_{\mathrm{j}}$ values, 848 although the difference is never significant. The differences can be explained by an 849 overweighting of $t_{0}$ and $t_{1}$, due to their role as anchor outcomes in the SP 850 measurements. While distorting the $\mathrm{s}_{\mathrm{j}} \mathrm{s}$ upwards, this bias hardly distorts the elicited 851 utility curvature. For the latter, not the values of $s_{j}$ or $t_{j}$ per se, but their equal 852 spacedness in utility units, is essential. This equal spacedness is affected only for the 853 interval $\left[\mathrm{U}\left(\mathrm{t}_{0}\right), \mathrm{U}\left(\mathrm{t}_{1}\right)\right]$ under the SP method, which then is somewhat underestimated.

854 For these reasons, it is preferable to investigate the curvature of utility, as opposed to 855 the directly observed inverse utility values (this is what our observations $t_{i}, s_{i}, c_{i}, d_{i}$, in 856 fact are). We investigate the curvature of utility through parametric fittings in the 857 following appendices. 


\section{Appendix C. Fitting Parametric Utility Families}

860

861

862

863

864

865

866

867

868

869

870

871

872

873

874

875

876

877

878

879

880

881

882

883

884

885

886

887

888

We fitted a number of parametric families to our data, and used the resulting parameters in the statistical analyses. All families hereafter were normalized so as to be on a same scale, and in this manner their numerical fits were compared. Because normalizations do not affect the empirical meaning of cardinal utility, we give nonnormalized formulas hereafter as their notation is simpler. First, we considered the two families that have been used most frequently in the literature. Parametric fittings directly concern the curvature of utility, and smoothen out irregularities in the data. A drawback is that the results may depend on the particular parametric families chosen. The power family is defined by

- $\mathrm{x}^{\mathrm{r}}$ if $\mathrm{r}>0$

- $\ln (\mathrm{x})$ if $\mathrm{r}=0$

- $-\mathrm{x}^{\mathrm{r}}$ if $\mathrm{r}<0$.

A rescaling $\mathrm{z}=\mathrm{x} / \mathrm{t}_{6}$ or $\mathrm{x} /\left(\mathrm{t}_{6}-\mathrm{t}_{0}\right)$ does not affect the preferences and, hence, need not be applied here. The translation $\mathrm{z}=\mathrm{x}-\mathrm{t}_{0}$ leads to another family that will be discussed later. [\#This family is most commonly used in the literature, and is also knows as the family of constant relative risk aversion (CRRA). Our results in Table 1 agree with those commonly found for individual choices with moderate stakes (Tversky \& Kahneman 1992). In macro-economics and finance, market data are considered that concern bigger stakes, and then usually lower (more negative) powers are required to achieve required levels of concavity (Aït-Sahalia \& Lo 2000; Bliss \& Panigirtzoglou 2004; Gregory, Lamarche, \& Smith 2002; Perraudin \& Sorensen 2000; van Soest, Das, \& Gong 2005). An additional reason why such studies find negative $r$ is that they assume expected utility so that risk aversion generated by probability weighting is (mis)modeled through concave utility.\#\}

The exponential family, also knows as the family of constant absolute risk aversion (CARA), is defined by

- $\mathrm{e}^{\mathrm{rz}}$ if $\mathrm{r}>0$

- $\mathrm{z}$ if $\mathrm{r}=0$

- $-\mathrm{e}^{\mathrm{rz}}$ if $\mathrm{r}<0$ 
889 where the domain $\left[\mathrm{t}_{0}, \mathrm{t}_{6}\right]$ is mapped into the unit interval through the transformation $\mathrm{z}$

$890=\left(\mathrm{x}-\mathrm{t}_{0}\right) /\left(\mathrm{t}_{6}-\mathrm{t}_{0}\right)$.

891 Several authors have suggested that utility is logarithmic (Bernoulli 1738; Savage

8921954 p. 94) but this family did not fit our data well. It allows for concave utility only,

893 whereas several participants exhibited convexities. Let us recall here that utility

894 functions, when corrected for probability weighting, are less concave than traditional

895 measurements have suggested. We also considered the translated power family where

$896 \mathrm{x}$ is replaced by $\mathrm{x}-\mathrm{t}_{0}$. This family supported the empirical hypotheses of this paper

897 equally well. We do not report its results because this family seems to be of limited

898 empirical interest: Its derivatives at $\mathrm{t}_{0}$ are extreme and the domain is not easily

899 extended below $\mathrm{t}_{0}$.

900 We introduce a new, third, parametric family, which we call the expo-power

901 family, and which is defined by

$902-\exp \left(-\frac{\mathrm{z}^{\mathrm{r}}}{\mathrm{r}}\right)$ for $\mathrm{r} \neq 0 ;^{4}$

$903-\frac{1}{\mathrm{z}}$ for $\mathrm{r}=0$.

904 We rescaled $z=\frac{x}{t_{6}}$. Figure 9 depicts some examples.

905 The expo-power family is a variation of a two-parameter family introduced by

906 Saha (1993). The rescaling $z=\frac{x}{t_{6}}$ maps our domain $\left[t_{0}, t_{6}\right]$ to $\left[t_{0} / t_{6}, 1\right] \subset[0,1]$. On

$907[0,1]$, the family exhibits some desirable features.

908 - $\mathrm{r}$ has a clear interpretation, being an anti-index of concavity (the smaller $\mathrm{r}$ the

909 more concave the function is).

910 - The family allows for both concave $(r \leq 1)$ and convex $(r \geq 2)$ functions.

911 - There exists a subclass of this family $(0 \leq \mathrm{r} \leq 1)$ that combines a number of

912 desirable features.

913 (i) The functions are concave;

914 (ii) The measure of absolute risk aversion, the Arrow-Pratt measure $-u^{\prime \prime}(x) / u^{\prime}(x)$

$915=(1-r) / x+x^{r-1}$, is decreasing in $\mathrm{x}$.

\footnotetext{
${ }^{4}$ For $\mathrm{r}$ close to zero, the strategically equivalent function $-\exp \left(-\frac{\mathrm{z}^{\mathrm{r}}}{\mathrm{r}}+1 / \mathrm{r}\right)$ is more tractable for numerical purposes.
} 
922

923

924

925

926

927

928

929

930

931

932

933

934

935

936

937

938

939

940

941

942

943

944

945

946 (iii) Finally, the measure of proportional risk aversion, $-x u^{\prime \prime}(x) / u^{\prime}(x)=1-r+x^{r}$, is increasing in $x^{5}$
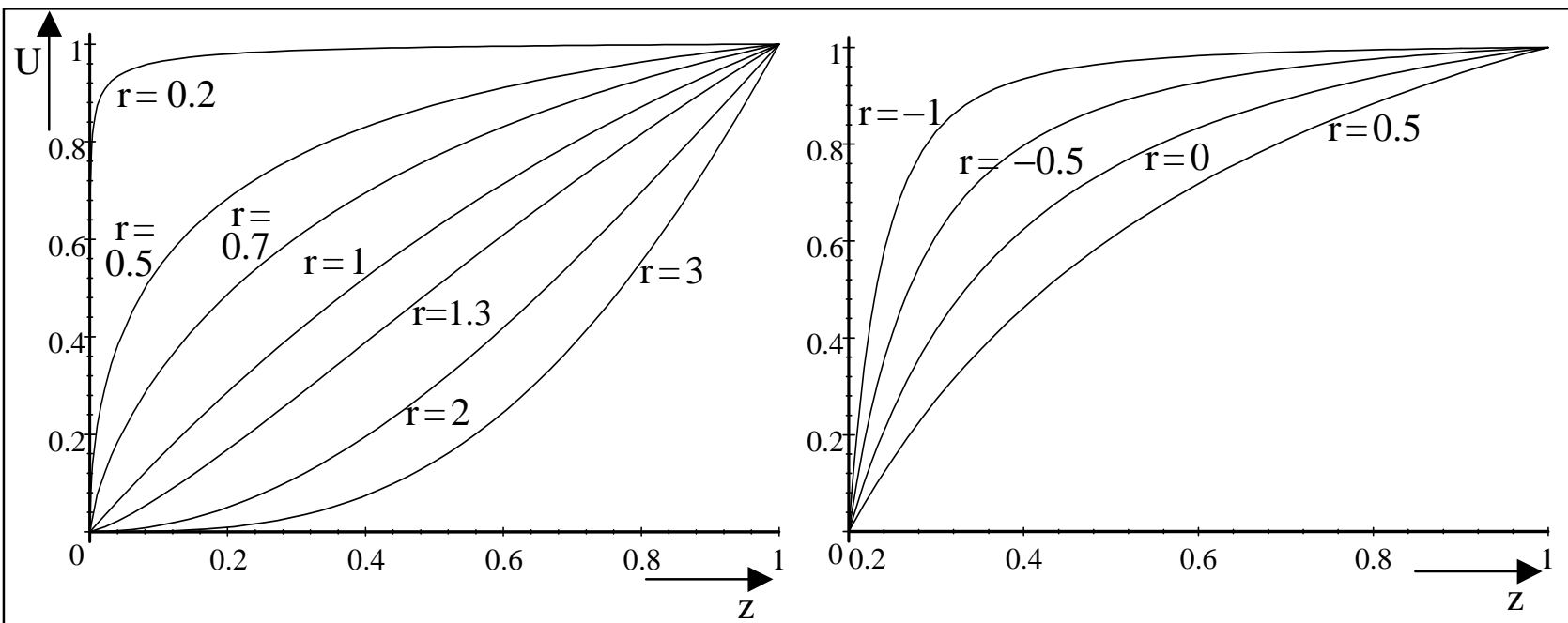

FIGURE 9. Some normalized curves of the expo-power family. For $r=1.3$, the curve is convex up to 0.40 and concave after.

Conditions (i), (ii), and (iii) are considered most relevant in the economics literature (Arrow 1971 p. 97; Binswanger 1981), but cannot be combined by any of the traditional parametric families. To allow for simultaneous satisfaction of all of these conditions, we developed the above variation of Saha's family. Necessarily, a oneparametric family with decreasing absolute risk aversion cannot contain linear functions and this is a drawback of our family. For $r=1.3$, the curves are close to linear.

Other families have been considered in the literature. Merton (1971) introduced the HARA family with hyperbolic absolute risk aversion. This family does not allow for convex functions, because of which it does not fit our data well. In addition, it does not allow for a combination of the three desirable features (i), (ii), and (iii) listed above.

Bell (1988) and Farquhar \& Nakamura (1987) characterized the family of all polynomial combinations of exponential functions. A subclass thereof is the general sumex family, consisting of all linear combinations of exponential functions and characterized by Nakamura (1996). In general, these families have many parameters

\footnotetext{
${ }^{5}$ So as to preserve this feature, we changed only the scale and not the location in the substitution $\mathrm{x} \mapsto \mathrm{z}(\mathrm{x})$.
} 
947 and useful subfamilies remain to be identified. We did consider one two-parameter 948 subfamily, being the sum of two exponential functions. The CE methods have only

949 three data points, which is insufficient to determine the parameters in any reliable 950 manner. The TO and SP methods have more data points and estimations of the two 951 parameters were obtained. The null hypothesis of identity of the parameters was not 952 rejected. Unfortunately, the parameter estimations were still unreliable and the test 953 had little power. Therefore, it is not reported here.

954

\section{Appendix D. Further Statistical Analyses of Parametric Estimations}

Table 3 gives descriptive statistics for individual parametric estimates. Figure 4

957 in the main text depicts the optimal parametric fittings of the expo-power family for a 958 representative agent. The parameters used there are: $\mathrm{r}=1.242$ for $\mathrm{TO}, \mathrm{r}=1.128$ for $959 \mathrm{SP}, \mathrm{r}=1.206$ for $\mathrm{CE}_{1 / 3}, \mathrm{r}=0.393$ for $\mathrm{CE}_{2 / 3}(\mathrm{EU}), \mathrm{r}=1.136$ for $\mathrm{CE}_{2 / 3}(\mathrm{PT})$. These 960 curves are based on averages of $t_{6}$ and $t_{1} / t_{6}, \ldots, t_{5} / t_{6}$ for TO, $s_{1} / t_{6}, \ldots$, and $s_{6} / t_{6}$ for $S P, t_{6}$ 961 and $\mathrm{c}_{1} / \mathrm{t}_{6}, \mathrm{c}_{2} / \mathrm{t}_{6}, \mathrm{c}_{3} / \mathrm{t}_{6}$ for $\mathrm{CE}_{1 / 3}$, and, finally, $\mathrm{t}_{6}$ and $\mathrm{d}_{1} / \mathrm{t}_{6}, \mathrm{~d}_{2} / \mathrm{t}_{6}, \mathrm{~d}_{3} / \mathrm{t}_{6}$ for $\mathrm{CE}_{2 / 3}(\mathrm{EU})$ and $962 \mathrm{CE}_{2 / 3}(\mathrm{PT})$. The curves for power and exponential fittings are very similar. 963 964 TABLE 3

\begin{tabular}{|c|c|c|c|c|c|c|c|c|c|}
\hline & \multicolumn{9}{|c|}{ Parametric Families } \\
\hline & \multicolumn{3}{|c|}{ Power } & \multicolumn{3}{|c|}{ Exponential } & \multicolumn{3}{|c|}{ Expo-power } \\
\hline & Median & Mean & St. Dev. & Median & Mean & St. Dev. & Median & Mean & St. Dev. \\
\hline TO & 0.77 & 0.91 & 0.70 & 0.28 & 0.29 & 0.90 & 1.29 & 1.33 & 0.75 \\
\hline SP & 0.64 & 1.10 & 2.04 & 0.42 & $-0.14^{\mathrm{a}}$ & 2.51 & 1.12 & 1.46 & 2.08 \\
\hline $\mathrm{CE}_{1 / 3}$ & 0.88 & 1.03 & 1.23 & 0.10 & 0.39 & 1.73 & 1.31 & 1.44 & 1.21 \\
\hline $\mathrm{CE}_{2 / 3}(\mathrm{EU})$ & -0.33 & -0.32 & 0.97 & 1.82 & 2.21 & 1.86 & 0.17 & 0.39 & 0.56 \\
\hline $\mathrm{CE}_{2 / 3}(\mathrm{PT})$ & 0.77 & 0.83 & 1.01 & 0.23 & 0.25 & 1.95 & 1.30 & 1.27 & 0.94 \\
\hline
\end{tabular}

${ }^{\text {a }}$ If one outlier, participant 28 , is excluded then the mean parameter is 0.18 and the standard deviation is 1.35 .

966 Wilcoxon tests rejected linear utility for the power family $\left(\mathrm{H}_{0}: \mathrm{r}=1\right)$, both for TO

$967(\mathrm{z}=-2.24, \mathrm{p}<0.05)$ and for SP $(\mathrm{z}=-2.32, \mathrm{p}<0.05)$, and likewise rejected linearity

968 for the exponential family $\left(\mathrm{H}_{0}: \mathrm{r}=0\right.$; TO: $\mathrm{z}=-2.72$, $\mathrm{p}<0.05$; SP: $\mathrm{z}=-2.42, \mathrm{p}<$

969 0.05). Because the expo-power family does not contain linear functions, no test of 970 linearity was carried out for this family. 
971 Table 4 presents the results of tests of equalities of utility parameters. The

972 answers of participant 44 for the $\mathrm{CE}_{2 / 3}$ questions could not be accommodated by the

973 exponential family and the parametric fitting did not converge. This participant is

974 excluded from the analysis of this family.

975

976 TABLE 4. Results of paired $t$-tests

\begin{tabular}{|c|c|c|c|c|c|c|}
\hline & \multicolumn{6}{|c|}{ Parametric Families } \\
\hline & \multicolumn{2}{|c|}{ Power } & \multicolumn{2}{|c|}{ Exponential } & \multicolumn{2}{|c|}{ Expo-power } \\
\hline & $t$ & $\mathrm{p}$ & $t$ & $\mathrm{p}$ & $t$ & $\mathrm{p}$ \\
\hline $\mathrm{TO}-\mathrm{SP}$ & $t_{46}=-0.17$ & .867 & $t_{45}=-0.63$ & .532 & $t_{46}=-0.42$ & .677 \\
\hline $\mathrm{TO}-\mathrm{CE}_{1 / 3}$ & $t_{33}=-0.54$ & .590 & $t_{32}=-0.41$ & .682 & $t_{33}=-0.67$ & .511 \\
\hline $\mathrm{TO}-\mathrm{CE}_{2 / 3}(\mathrm{EU})$ & $t_{33}=6.76$ & .000 & $t_{32}=-6.27$ & .000 & $t_{33}=6.25$ & .000 \\
\hline $\mathrm{TO}-\mathrm{CE}_{2 / 3}(\mathrm{PT})$ & $t_{33}=0.002$ & .999 & $t_{32}=0.070$ & .945 & $t_{33}=0.23$ & .820 \\
\hline $\mathrm{SP}-\mathrm{CE}_{1 / 3}$ & $t_{33}=0.35$ & .730 & $t_{32}=-1.67$ & .105 & $t_{33}=0.61$ & .546 \\
\hline $\mathrm{SP}-\mathrm{CE}_{2 / 3}(\mathrm{EU})$ & $t_{33}=4.05$ & .000 & $t_{32}=-4.76$ & .000 & $t_{33}=2.98$ & .005 \\
\hline $\mathrm{SP}-\mathrm{CE}_{2 / 3}(\mathrm{PT})$ & $t_{33}=0.69$ & .493 & $t_{32}=-1.16$ & .255 & $t_{33}=0.91$ & .368 \\
\hline $\mathrm{CE}_{1 / 3}-\mathrm{CE}_{2 / 3}(\mathrm{EU})$ & $t_{33}=5.23$ & .000 & $t_{32}=-7.19$ & .000 & $t_{33}=5.27$ & .000 \\
\hline $\mathrm{CE}_{1 / 3}-\mathrm{CE}_{2 / 3}(\mathrm{PT})$ & $t_{33}=0.57$ & .572 & $t_{32}=0.43$ & .672 & $t_{33}=0.91$ & .370 \\
\hline $\mathrm{CE}_{2 / 3}(\mathrm{EU})-\mathrm{CE}_{2 / 3}(\mathrm{PT})$ & $t_{33}=-13.34$ & .000 & $t_{32}=10.09$ & .000 & $t_{33}=-8.13$ & .000 \\
\hline
\end{tabular}

977

978 The conclusions are the same for all families and agree with the conclusions in the

979 main text. The $\mathrm{CE}_{2 / 3}$ measurements, when analyzed through EU, differ significantly

980 from all the other measurements. The other measurements, including the $\mathrm{CE}_{2 / 3}$

981 measurements when analyzed through PT, agree.

982 The statistics for analyses of variance with repeated measures described in the

983 main text concerned the expo-power family. The other families give very similar

984 statistics and the same conclusions.

985

986 References

987 Abdellaoui, Mohammed (2000), "Parameter-Free Elicitation of Utilities and

988 Probability Weighting Functions," Management Science 46, 1497-1512.

989 Aït-Sahalia, Yacine \& Andrew W. Lo (2000), "Nonparametric Risk Management and

990 Implied Risk Aversion," Journal of Econometrics 94, 9-51. 
991 Allais, Maurice (1953), "Fondements d'une Théorie Positive des Choix Comportant

992

993

994

995

996

997

998

999

1000

1001

1002

1003

1004

1005

1006

1007

1008

1009

1010

1011

1012

1013

1014

1015

1016

1017

1018

1019

1020

1021

1022 un Risque et Critique des Postulats et Axiomes de l'Ecole Américaine," Colloques Internationaux du Centre National de la Recherche Scientifique (Econométrie) 40, 257-332. Paris: Centre National de la Recherche Scientifique. Translated into English, with additions, as "The Foundations of a Positive Theory of Choice Involving Risk and a Criticism of the Postulates and Axioms of the American School," in Maurice Allais \& Ole Hagen (1979, Eds.), Expected Utility Hypotheses and the Allais Paradox, 27-145, Reidel, Dordrecht, The Netherlands. Alt, Franz (1936), "Über die Messbarkeit des Nutzens." Zeitschrift für Nationalökonomie 7, 161-169. Translated into English by Siegfried Schach (1971), "On the Measurability of Utility." In John S. Chipman, Leonid Hurwicz, Marcel K. Richter, \& Hugo F. Sonnenschein (Eds.), Preferences, Utility, and Demand, Hartcourt Brace Jovanovich, New York, Chapter 20.

Arrow, Kenneth J. (1971), "Essays in the Theory of Risk Bearing." North-Holland, Amsterdam.

Barrios, Carolina (2003), “Une Réconciliation de la Mesure de l’Utilité à l'Aide de la “Prospect Theory": Une Approche Experimentale," Ph.D. dissertation, ENSAM, Paris, France.

Baumol, William J. (1958), "The Cardinal Utility Which is Ordinal," Economic Journal 68, 665-672.

Bayoumi, Ahmed \& Donald A. Redelmeier (2000), "Decision Analysis with Cumulative Prospect Theory," Medical Decision Making 20, 404-412.

Bell, David E. (1988), "One-Switch Utility Functions and a Measure of Risk," Management Science 34, 1416-1424.

Bentham, Jeremy (1789), "The Principles of Morals and Legislation." At the Clarendom Press, Oxford.

Bernoulli, Daniel (1738), "Specimen Theoriae Novae de Mensura Sortis," Commentarii Academiae Scientiarum Imperialis Petropolitanae 5, 175-192. Translated into English by Louise Sommer (1954), "Exposition of a New Theory on the Measurement of Risk," Econometrica 22, 23-36. Reprinted in Alfred N. Page (1968, Ed.), Utility Theory: A Book of Readings, Chapter 11, Wiley, New York. Revised translation in William J. Baumol \& 
1023

1024

1025

1026

1027

1028

1029

1030

1031

1032

1033

1034

1035

1036

1037

1038

1039

1040

1041

1042

1043

1044

1045

1046

1047

1048

1049

1050

1051

1052

1053

1054

1055

Stephen M. Goldfeld (Eds., 1968), Precursors in Mathematical Economics: An Anthology. Clowes and Sons, London, Selection 2, 15-26.

Binmore, Kenneth G. (1999), "Why Experiments in Economics?," Economic Journal 109, F16-F24.

Binswanger, Hans P. (1981), "Attitudes towards Risk: Theoretical Implications of an Experiment in Rural India," Economic Journal 91, 867-890.

Birnbaum, Michael H. \& Juan B. Navarrete (1998), "Testing Descriptive Utility Theories: Violations of Stochastic Dominance and Cumulative Independence," Journal of Risk and Uncertainty 17, 49-78.

Birnbaum, Michael H. \& Sara E. Sutton (1992), "Scale Convergence and Utility Measurement," Organizational Behavior and Human Decision Processes 52, $183-215$.

Blaug, Mark (1962), "Economic Theory in Retrospect." Cambridge University Press, Cambridge. $\left(5^{\text {th }}\right.$ ed. 1997$)$

Bleichrodt, Han (2002), "A New Explanation for the Difference between SG and TTO Utilities," Health Economics 11, 447-456.

Bleichrodt, Han \& José Luis Pinto (2000), "A Parameter-Free Elicitation of the Probability Weighting Function in Medical Decision Analysis," Management Science 46, 1485-1496.

Bleichrodt, Han, José Luis Pinto, \& Peter P. Wakker (2001), "Making Descriptive Use of Prospect Theory to Improve the Prescriptive Use of Expected Utility," Management Science 47, 1498-1514.

Bliss, Robert R. \& Nikolaos Panigirtzoglou (2004), "Option-Implied Risk Aversion Estimates," Journal of Finance 59, 407-446.

Bostic, Raphael, Richard J. Herrnstein, \& R. Duncan Luce (1990), "The Effect on the Preference-Reversal Phenomenon of Using Choice Indifferences," Journal of Economic Behavior and Organization 13, 193-212.

Bouyssou, Denis \& Jean-Claude Vansnick (1988), "A Note on the Relationships between Utility and Value Functions." In Bertrand R. Munier (Ed.), Risk, Decision and Rationality, 103-114, Reidel, Dordrecht, The Netherlands. Breiter, Hans C., Ithak Aharon, Daniel Kahneman, Anders Dale, \& Peter Shizgal (2001), "Functional Imaging of Neural Responses to Expectancy and Experience of Monetary Gains and Losses," Neuron 30, 619-639. 
1056 Broome, John R. (1991), "Weighing Goods." Basil Blackwell, Oxford, UK.

1057 Camerer, Colin F. (1995), "Individual Decision Making." In John H. Kagel \& Alvin

1058 E. Roth (Eds.), Handbook of Experimental Economics, 587-703, Princeton

$1059 \quad$ University Press, Princeton, NJ.

1060 Camerer, Colin F. \& Teck-Hua Ho (1994), "Violations of the Betweenness Axiom

1061 and Nonlinearity in Probability," Journal of Risk and Uncertainty 8, 167-196.

1062 Camerer, Colin F. \& Robin M. Hogarth (1999), "The Effects of Financial Incentives

1063 in Experiments: A Review and Capital-Labor-Production Framework," Journal of

1064 Risk and Uncertainty 19, 7-42.

1065 Cooter, Robert D. \& Peter Rappoport (1984), "Were the Ordinalists Wrong about

1066 Welfare Economics?," Journal of Economic Literature 22, 507-530.

1067 Cramer, Gabriel (1728), Letter from Cramer to Nicholas Bernoulli. Translated into

1068 English by Louise Sommer in Bernoulli, Daniel (1954), "Exposition of a New

1069 Theory on the Measurement of Risk," Econometrica 22, 23-36.

1070 Debreu, Gérard (1959), "Cardinal Utility for Even-Chance Mixtures of Pairs of Sure-

1071 Prospects," Review of Economic Studies 26, 174-177.

1072 Debreu, Gérard (1976), "Least Concave Utility Functions," Journal of Mathematical

1073 Economics 3, 121-129.

1074 Edgeworth, F. Ysidro (1881), "Mathematical Physics, An Essay on the Application of

1075 Mathematics to the Moral Sciences."

1076 Reprinted 1967, M. Kelley, New York.

Ellingsen, Tore (1994), "Cardinal Utility: A History of Hedinometry." In Maurice Allais \& Ole Hagen (Eds.), Cardinalism; A Fundamental Approach, 105-165, Kluwer Academic Publishers, Dordrecht, The Netherlands.

Ellsberg, Daniel (1954), "Classic and Current Notions of 'Measurable Utility',"

$1081 \quad$ Economic Journal 62, 528-556.

1082 Ellsberg, Daniel (1961), "Risk, Ambiguity and the Savage Axioms," Quarterly

1083 Journal of Economics 75, 643-669.

1084 Farquhar, Peter H. \& Yutaka Nakamura (1987), "Constant Exchange Risk Properties," 1085 Operations Research 35, 206-214.

1086 Fellner, Wiliam (1961), "Distortion of Subjective Probabilities as a Reaction to 1087 Uncertainty," Quarterly Journal of Economics 75, 670-689. 
1088 Fishburn, Peter C. (1978), "On Handa's "New Theory of Cardinal Utility" and the Maximization of Expected Return," Journal of Political Economy 86, 321-324.

1090 Frey, Bruno S. \& Felix Oberholzer-Gee (1997), "The Cost of Price Incentives: An Empirical Analysis of Motivation Crowding-Out," American Economic Review $87,746-755$.

1093

Frey, Bruno S. \& Alois Stutzer (2000), "Happiness, Economy and Institutions," Economic Journal 110, 918-938.

Friedman, Milton \& Leonard J. Savage (1948), "The Utility Analysis of Choices Involving Risk," Journal of Political Economy 56, 279-304.

Frisch, Ragnar (1926), "Sur un Problème d'Economie Pure," Norsk Matematisk Forenings Skrifter Serie 1 16, 1-40. Translated into English by John S. Chipman, "On a Problem in Pure Economics." In John S. Chipman, Leonid Hurwicz, Marcel K. Richter, \& Hugo F. Sonnenschein (1971, Eds.), Preferences, Utility, and Demand, Chapter 19, Hartcourt, New York.

Gilboa, Itzhak (1987), "Expected Utility with Purely Subjective Non-Additive Probabilities," Journal of Mathematical Economics 16, 65-88.

Gilboa, Itzhak \& David Schmeidler (1995), "Case-Based Decision Theory," Quarterly Journal of Economics 110, 605-639.

Gilboa, Itzhak \& David Schmeidler (2001), "A Cognitive Model of Individual WellBeing," Social Choice and Welfare 18, 269-288.

Gneezy, Uri, \& Aldo Rustichini (2000), "Pay Enough or Don't Pay at All," Quarterly Journal of Economics 115, 791-810.

Gold, Marthe R., Joanna E. Siegel, Louise B. Russell, \& Milton C. Weinstein (1996), "Cost-Effectiveness in Health and Medicine." Oxford University Press, New

1113 Gonzalez, Richard \& George Wu (1999), "On the Shape of the Probability Weighting 1114 Function," Cognitive Psychology 38, 129-166.

1115 Gregory, Allen W., Jean-François Lamarche, \& Gregor W. Smith (2002),

1116 "Information-Theoretic Estimation of Preference Parameters: Macroeconomic Applications and Simulation Evidence," Journal of Econometrics 107, 213-233.

1118 Gregory, Robin, Sarah Lichtenstein, \& Paul Slovic (1993), "Valuing Environmental 1119 Resources: A Constructive Approach," Journal of Risk and Uncertainty 7, $1120 \quad 177-197$. 
1121 Grether, David M. \& Charles R. Plott (1979), "Economic Theory of Choice and the 1122 Preference Reversal Phenomenon," American Economic Review 69, 623-638.

1123 Gul, Faruk (1991), "A Theory of Disappointment Aversion," Econometrica 59, $1124 \quad 667-686$.

1125 Handa, Jagdish (1977), "Risk, Probabilities, and a New Theory of Cardinal Utility," $1126 \quad$ Journal of Political Economy 85, 97-122.

1127 Harbaugh, William T., Kate Krause, \& Lise Vesterlund (2001), "Prospect Theory in 1128 Choice and Pricing Tasks,"

1129 Harsanyi, John C. (1955), "Cardinal Welfare, Individualistic Ethics, and Interpersonal 1130 Comparisons of Utility," Journal of Political Economy 63, 309-321.

1131 Hershey, John C. \& Paul J.H. Schoemaker (1985), "Probability versus Certainty

1132 Equivalence Methods in Utility Measurement: Are They Equivalent?,"

1133 Management Science 31, 1213-1231.

1134 Hertwig, Ralf \& Andreas Ortmann (2001), "Experimental Practices In Economics: A 1135 Challenge for Psychologists?," Behavioral and Brain Sciences 24, 383-403.

1136 Hicks, John R. \& Roy G.D. Allen (1934), "A Reconsideration of the Theory of Value:

1137 I; II," Economica 1, 52-75; 196-219.

1138 Houthakker, Hendrik S. (1950), "Revealed Preference and the Utility Function," 1139 Economica, N.S. 17, 159-174.

1140 Kachelmeier, Steven J. \& Mohamed Shehata (1992), "Examining Risk Preferences

1141 under High Monetary Incentives: Experimental Evidence from the People's 1142 Republic of China," American Economic Review 82, 1120-1141; for comment 1143 see Steven J. Kachelmeier \& Mohammed Shehata (1994), American Economic $1144 \quad$ Review 84, 1104-1106.

1145 Kahneman, Daniel (1994), "New Challenges to the Rationality Assumption," Journal 1146 of Institutional and Theoretical Economics 150, 18-36.

1147 Kahneman, Daniel \& Amos Tversky (1979), "Prospect Theory: An Analysis of 1148 Decision under Risk," Econometrica 47, 263-291.

1149 Kahneman, Daniel \& Amos Tversky (2000, Eds.), "Choices, Values, and Frames." $1150 \quad$ Cambridge University Press, New York.

1151 Kapteyn, Arie (1994), "The Measurement of Household Cost Functions: Revealed 1152 Preference versus Subjective Measures," Journal of Population Economics 7, $1153 \quad 333-350$. 
1154 Karmarkar, Uday S. (1978), "Subjectively Weighted Utility: A Descriptive Extension of the Expected Utility Model," Organizational Behavior and Human Performance 21, 61-72.

Karni, Edi \& Zvi Safra (1990), "Rank-Dependent Probabilities," Economic Journal $100,487-495$.

Krzysztofowicz, Roman \& John B. Koch (1989), "Estimation of Cardinal Utility

Lichtenstein, Sarah \& Paul Slovic (1971), "Reversals of Preference between Bids and Choices in Gambling Decisions," Journal of Experimental Psychology 89, 46-55.

Loewenstein, George F. (1999), "Experimental Economics from the Vantage-Point of Behavioural Economics," Economic Journal 109, F25-F34.

Loomes, Graham \& Robert Sugden (1982), "Regret Theory: An Alternative Theory of Rational Choice under Uncertainty," Economic Journal 92, 805-824.

Loomes, Graham, Chris Starmer, \& Robert Sugden (2003), "Do Anomalies Disappear in Repeated Markets?," The Economic Journal 113, C153-C166.

Machina, Mark J. (1982), " 'Expected Utility' Analysis without the Independence Axiom," Econometrica 50, 277-323.

1171 Manski, Charles F. (2004), "Measuring Expectations," Econometrica 72, 1329-1376.

1172 Marshall, Alfred (1890), "Principles of Economics." $8^{\text {th }}$ edition 1920 (9 ${ }^{\text {th }}$ edition 1173 1961), MacMillan, New York.

1174 McCord, Mark R. \& Richard de Neufville (1983), "Fundamental Deficiency of Expected Utility Decision Analysis." In Simon French, R. Hartley, L.C. Thomas, \& Douglas J. White (Eds.), Multi-Objective Decision Making, 279-305, Academic Press, New York.

McCord, Mark R. \& Richard de Neufville (1984), "Utility Dependence on Probability: An Empirical Demonstration," Large Scale Systems 6, 91-103.

McCord, Mark R. \& Richard de Neufville (1986), " "Lottery Equivalents ": Reduction of the Certainty Effect Problem in Utility Assessment," Management Science 32, $56-60$.

Merton, Robert C. (1971), "Optimum Consumption and Portfolio Rules in a Continuous-Time Model," Journal of Economic Theory 3, 373-413. 
1187 Ng, Yew-Kwang (1997), "A Case for Happiness, Cardinalism, and Interpersonal Comparability," Economic Journal 107, 1848-1858.

Pareto, Vilfredo (1906), "Manuele di Economia Politica." Piccolo Biblioteca Scientifica, Milan. Translated into English by Ann S. Schwier (1971), "Manuel of Political Economy," MacMillan, London. Translated into French in 1927 as "Manuel d'Economie Politique." Giard, Paris, second edition.

Pennings, Joost M.E. \& Ale Smidts (2000), "Assessing the Construct Validity of Risk Attitude," Management Science 46, 1337-1348.

Perraudin, William R.M. \& Bent E. Sorensen (2000), "The Demand for Risky Assets: Sample Selection and Household Portfolios," Journal of Econometrics 97, $117-144$.

Prelec, Drazen (1998), "The Probability Weighting Function," Econometrica 66, 497-527.

Quiggin, John (1982), "A Theory of Anticipated Utility," Journal of Economic Behaviour and Organization 3, 323-343.

Rabin, Matthew (2000), "Risk Aversion and Expected-utility Theory: A Calibration Theorem," Econometrica 68, 1281-1292.

Ramsey, Frank P. (1931), "Truth and Probability." In "The Foundations of Mathematics and other Logical Essays," 156-198, Routledge and Kegan Paul, London. Reprinted in Henry E. Kyburg Jr. \& Howard E. Smokler (1964, Eds.), Studies in Subjective Probability, 61-92, Wiley, New York. ( $2^{\text {nd }}$ edition 1980, Krieger, New York.)

Revicki, Dennis A. \& Robert M. Kaplan (1993), "Relationship between Psychometric and Utility-Based Approaches to the Measurement of Health-Related Quality of Life," Quality Life Research 2, 477-487.

Robinson, Angela, Graham Loomes, \& Michael Jones-Lee (2001), "Visual Analog Scales, Standard Gambles, and Relative Risk Aversion," Medical Decision Making 21, 17-21.

Robson, Arthur J. (2001), "Why Would Nature Give Individuals Utility Functions?," The Journal of Political Economy 109, 900-914. 
1219 Saha, Atanu (1993), "Expo-power Utility: A Flexible Form for Absolute and Relative Aversion," American Journal of Agricultural Economics 75, 905-913.

1221 Samuelson, Paul A. (1937), "A Note on Measurement of Utility," Review of Economic Studies 4 (issue 2, February 1937), 155-161.

Samuelson, Paul A. (1938a), "The Numerical Representation of Ordered Classifications and the Concept of Utility," Review of Economic Studies 6 (Issue 1, October 1938), 65-70.

Samuelson, Paul A. (1938b), "A Note on the Pure Theory of Consumer's Behaviour," Economica, N.S. 5, 61-71, 353-354.

Samuelson, Paul A. (1950), "The Problem of Integrability in Utility Theory," Economica, N.S. 17, 355-385.

Savage, Leonard J. (1954), "The Foundations of Statistics." Wiley, New York. (Second edition 1972, Dover Publications, New York.)

Schmeidler, David (1989), "Subjective Probability and Expected Utility without Additivity," Econometrica 57, 571-587.

Sen, Amartya K. (1974), "Informational Bases of Alternative Welfare Approaches. Aggregation and Income Distribution," Journal of Public Economics 3, 387-403.

Shafir, Eldar, Peter A. Diamond, \& Amos Tversky (1997), "Money Illusion," Quarterly Journal of Economics 112, 341-374.

Simon, Herbert A. (1955), "A Behavioral Model of Rational Choice," Quarterly Journal of Economics 69, 99-118.

Skinner, Burrhus F. (1971), "Beyond Freedom and Dignity." Knopf, N.Y.

Smith, Vernon L. (1982), "Microeconomic Systems as an Experimental Science," American Economic Review 72, 923-955.

Starmer, Chris (2000), "Developments in Non-Expected Utility Theory: The Hunt for a Descriptive Theory of Choice under Risk," Journal of Economic Literature 38, $332-382$.

Stigler, George J. (1950), "The Development of Utility Theory: I; II," Journal of Political Economy 58, 307-327; 373-396. Reprinted in Alfred N. Page (1968), Utility Theory: A Book of Readings, Wiley, New York, 55-119.

Tinbergen, Jan (1991), "On the Measurement of Welfare," Journal of Econometrics $50,7-13$. 
1252 Torrance, George W., Michael H. Boyle, \& Sargent P. Horwood (1982), "Application of Multi-Attribute Utility Theory to Measure Social Preferences for Health States," Operations Research 30, 1043-1069.

Tversky, Amos \& Craig R. Fox (1995), "Weighing Risk and Uncertainty," Psychological Review 102, 269-283.

Tversky, Amos \& Daniel Kahneman (1992), "Advances in Prospect Theory: Cumulative Representation of Uncertainty," Journal of Risk and Uncertainty 5, 297-323.

van Praag, Bernard M.S. (1968), "Individual Welfare Functions and Consumer Behavior." North-Holland, Amsterdam, 1968.

Van Praag, Bernard M.S. (1991), "Ordinal and Cardinal Utility: An Integration of the Two Dimensions of the Welfare Concept," Journal of Econometrics 50, 69-89. Supply Model with Flexible Preferences," Journal of Econometrics 107, 345-374.

Varian, Hal R. (1993), "Intermediate Microeconomics." Norton, New York. Economic Behavior." Princeton University Press, Princeton NJ.

von Winterfeldt, Detlof \& Ward Edwards (1986), "Decision Analysis and Behavioral Research." Cambridge University Press, Cambridge, UK.

Wakker, Peter P. \& Daniel Deneffe (1996), "Eliciting von Neumann-Morgenstern Utilities when Probabilities Are Distorted or Unknown," Management Science $42,1131-1150$.

Wakker, Peter P. \& Anne M. Stiggelbout (1995), "Explaining Distortions in Utility Elicitation through the Rank-Dependent Model for Risky Choices," Medical Decision Making 15, 180-186.

Watson, John B. (1913), "Psychology as the Behaviorist Views It," Psychological Review 20, 158-177.

Weber, Elke U. (1994), "From Subjective Probabilities to Decision Weights: The Effects of Asymmetric Loss Functions on the Evaluation of Uncertain Outcomes and Events," Psychological Bulletin 115, 228-242. 
1285 Yaari, Menahem E. (1987), "The Dual Theory of Choice under Risk," Econometrica $1286 \quad 55,95-115$.

1287 Zellner, Arnold (1971), An Introduction to Bayesian Inference in Econometrics.

1288 Wiley, New York.

1289 Zeuthen, Frederik (1937), "On the Determinateness of the Utility Function," Review 1290 of Economic Studies 4, 236-239.

1291 Köbberling \& Wakker waar? 